Escuela de

Postgrado de

Marketing

Internacional

\title{
Título: Exportación de servicios de diseño e identidad corporativa desde el Estudio Demaro
}

Trabajo Científico Libre para la obtención del grado de Magister en Marketing Internacional de

la Escuela de Posgrado en Marketing Internacional - Facultad de Ciencias Económicas -

Universidad Nacional de La Plata

Profesor Director de Tesis:

Prof. Ing. José Pedro Pagano
Presentado por:

Lucía Medina 
EXPORTACIÓN DE SERVICIOS DE DISEÑO E IDENTIDAD CORPORATIVA DESDE EL ESTUDIO DEMARO 
EXPORTACIÓN DE SERVICIOS DE DISEÑO E IDENTIDAD CORPORATIVA DESDE EL ESTUDIO DEMARO

\section{Prólogo y Agradecimientos}

Para terminar la Maestría de Marketing Internacional con el desarrollo de la tesis, plantee complementar mi carrera de grado: Diseño en Comunicación Visual, con la carrera de posgrado y así surgió el tema de la presente tesis: Exportación de servicios de diseño e identidad corporativa desde el Estudio Demaro.

Asimismo, mi interés por aplicar todo lo aprehendido a la realidad me llevó a buscar el aval del estudio de diseño en el cual trabajo hace 8 años, pudiendo introducir su perfil corporativo al análisis.

La exportación de servicios es un tema de alta relevancia para los países en desarrollo ya que brindan un gran valor agregado social y económico; es por ello que creo que se debe promover la participación de las pymes en dicho tema.

Actualmente el diseño y la identidad corporativa son servicios que están creciendo respecto a su perfil exportador y necesitan de mayor toma de datos específicos y apalancarse en disciplinas ya posicionadas. Considero que dichos servicios son imprescindibles para mejorar el desempeño de las empresas en un contexto global y competitivo.

Delineé un plan de marketing para que el Estudio Demaro logre exportar sus servicios a mediano y largo plazo, comenzando por la región latinoamericana para adquirir experiencia y lograr un óptimo accionar exportador.

Agradezco profundamente la calidad académica e interpersonal del Prof.Ing José Pedro Pagano que me guió a lo largo del desarrollo de la presente tesis con gran dedicación profesional aportando toda su experiencia para lograr superarme a mí misma. 
Índice

Introducción Metodológica .............................................................................................6

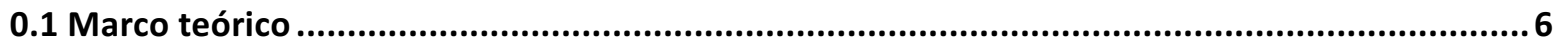

0.2 Objetivo general .............................................................................................................

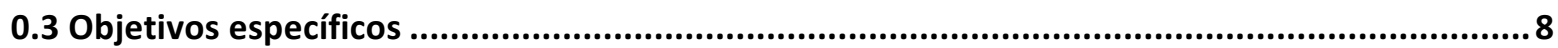

0.4 Metodología ...........................................................................................................................

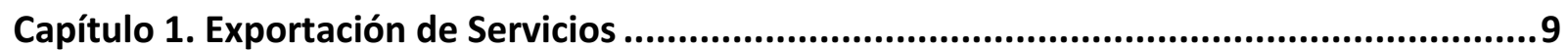

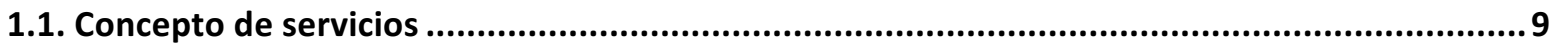

1.2. Concepto y marco legal de la exportación de servicios .......................................................... 10

1.3. La exportación de servicios en el mundo............................................................................... 11

1.4. Las estadísticas mundiales de los comercios de servicios y su composición: los nuevos sectores dinámicos ........................................................................................................................ 12

1.5. La exportación de servicios en América Latina. .................................................................14

1.6 La exportación de servicios en Argentina y su promoción ......................................................17

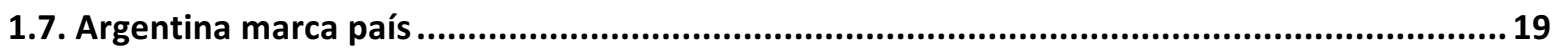

1.8. El mercado meta y las PyMEs en la exportación argentina de servicios ...................................2 21

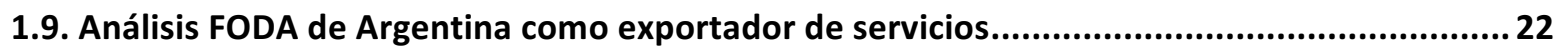

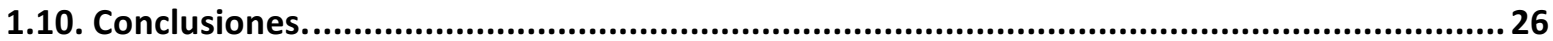

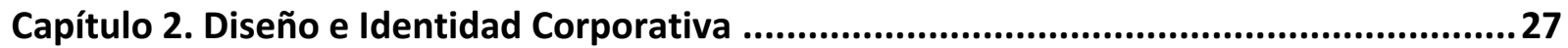

2.1.Definiciones de diseño e identidad corporativa .....................................................................2 27

2.2. El valor del diseño y su significación para las empresas globales ..........................................28

2.3. Percepciones del diseño gráfico latinoamericano y argentino ..................................................30

2.4. Casos análogos. Servicios de arquitectura. Servicios audiovisuales. .........................................32

2.5. El diseño como disciplina exportable. Estudios de diseño que exportan...................................35

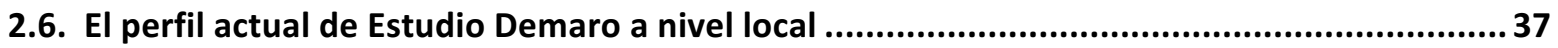

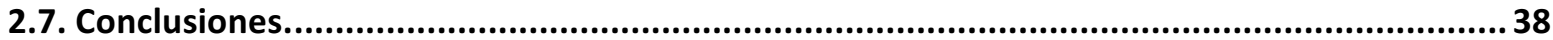

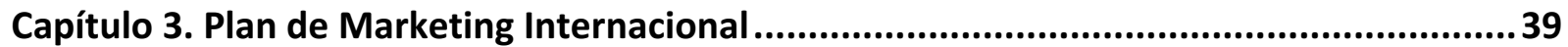

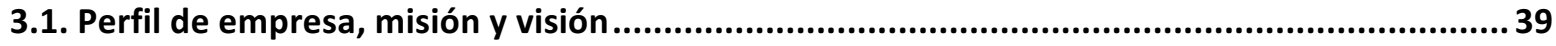

3.2. Objetivo general y objetivos específicos del Plan de Marketing .............................................4 41

3.3. Estrategia del Plan de Marketing ……….............................................................................. 41

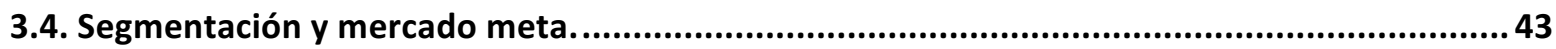

3.5. Mezcla del Plan de Marketing: Servicios. (Producto) …….......................................................4

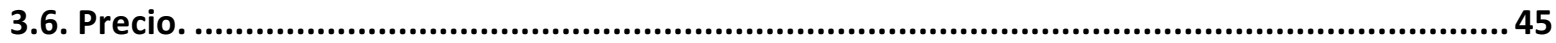




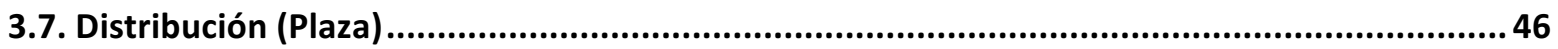

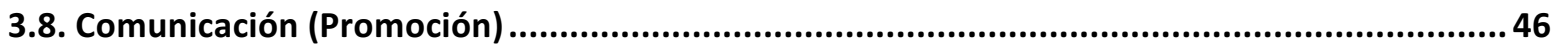

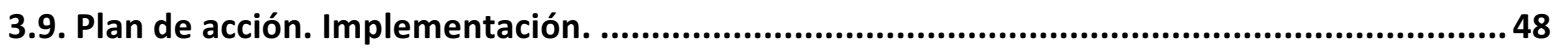

3.9.1 Descripción de metodología de trabajo de Estudio Demaro ................................................. 49

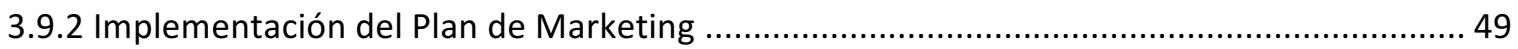

3.10 Conclusiones del Plan de Marketing Internacional ..........................................................51

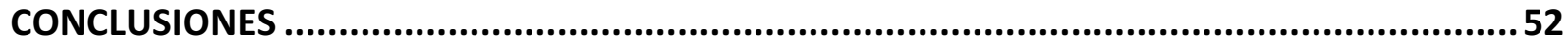

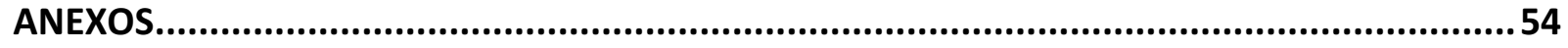

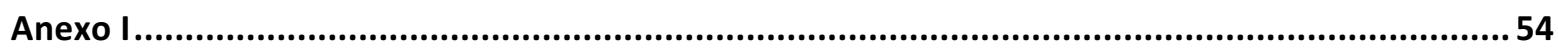

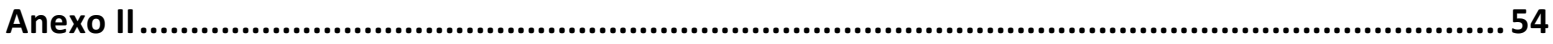

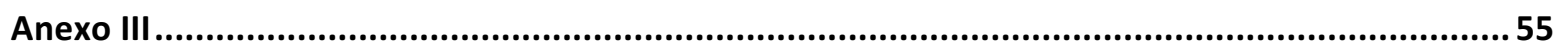

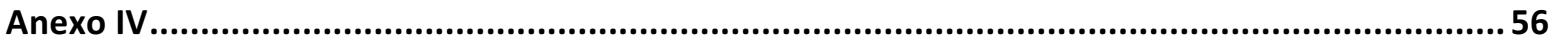

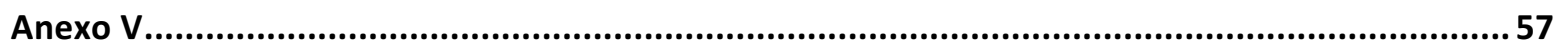

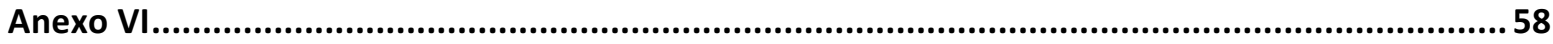

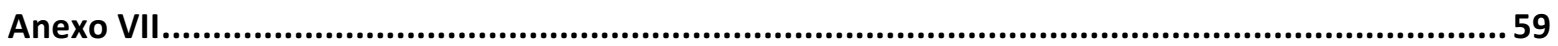

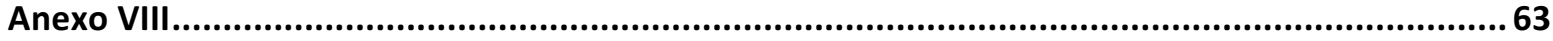

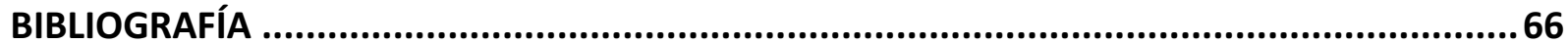


EXPORTACIÓN DE SERVICIOS DE DISEÑO E IDENTIDAD CORPORATIVA DESDE EL ESTUDIO DEMARO

\section{Introducción Metodológica}

\subsection{Marco teórico}

En primera instancia es necesario remarcar que, como lo define Philip Kotler (1993: $514)^{1}$, la exportación de servicios posee un rasgo diferencial: el producto a comercializar es intangible, y puede o no relacionarse a un producto físico. Tal como lo desarrollan Zeithalm y Bitner $(2002)^{2}$, sus particularidades entonces se relacionan directamente con la manera de brindar el servicio, es decir, con las personas que lo ofrecen.

Asimismo, se suman otros rasgos como la heterogeneidad, la inseparabilidad y el carácter perecedero, los cuales deben ser tenidos en cuenta para brindar un enfoque estratégico a la hora de desarrollar el plan de marketing.

Por otro lado, conocer los diferentes modos de suministro que puede asumir la exportación de servicios nos permitirá enmarcar el presente proyecto. Definidos en el Acuerdo General sobre el Comercio de Servicios (GATS) ${ }^{3}$ son: el suministro transfronterizo, el consumo en el extranjero, la presencia comercial y la presencia de personas físicas. En el caso del comercio transfronterizo es el servicio el que atraviesa la frontera sin implicar el movimiento de personas; por el contrario el consumo en el exterior significa que el cliente es el que viaja al país en el cual se proporciona el servicio. La presencia comercial, como su nombre lo indica, es el modo en el que el proveedor establece una presencia comercial en el exterior y por último, la presencia de personas físicas refiere a que el que brinda el servicio se traslada de forma temporal a otro país para brindarlo.

En este caso en particular se pretende comercializar en el exterior servicios de diseño e identidad corporativa, disciplinas que trabajan principalmente con recursos estéticos,

\footnotetext{
${ }^{1}$ Kotler, P. (1987). Fundamentos de Mercadotecnia .México: Prentice Hall.

${ }^{2}$ Zeithaml, V. y Bitner, M.J. (2002). Marketing de Servicios, Un enfoque de integración del cliente a la empresa. México: McGraw-Hill.

${ }^{3}$ WTO. (2014).Acuerdo General de Servicios, Organización Mundial de Comercio. Recuperado el 9 de Diciembre de 2013 de http://www.wto.org/spanish/tratop_s/serv_s/gatsqa_s.htm
} 
EXPORTACIÓN DE SERVICIOS DE DISEÑO E IDENTIDAD CORPORATIVA DESDE EL ESTUDIO DEMARO

visuales y comunicacionales. Sin embargo, Adrián Pierini (2012) ${ }^{4}$ afirma que detrás de los recursos gráficos debe existir una estrategia, un fundamento de lo visual. Respecto a ello, Roberto Fuentes $(2005: 28)^{5}$ indica que la acción de diseñar nace siempre de una necesidad de comunicación en particular. Por último, Norberto Chaves $(2012){ }^{6}$ sostiene que la disciplina ha vivido un gran progreso, en sus comienzos ligada sólo al diseño de marcas, y actualmente abocándose al desarrollo de estrategias integrales de comunicación e identidad que abarcan a la empresa de forma completa. Hoy, la identidad corporativa comprende desde la marca hasta la forma de atención del personal de la empresa; todo aquello que forme parte de su imagen.

Para el desarrollo de este proyecto se empleará a Estudio Demaro ${ }^{7}$ como modelo. Un estudio de diseño de la ciudad de La Plata, fundado hace 18 años por el diseñador en comunicación visual Damián A. Demaro. Durante esos años el estudio ha desarrollado proyectos integrales de identidad y comunicación para distintos rubros: gastronómico, salud, software, indumentaria, agropecuario, entre otros. Actualmente, su perfil de clientes abarca a pymes en crecimiento de la ciudad de La Plata y la Provincia de Buenos Aires.

Estudio Demaro tiene como objetivo desarrollarse como empresa exportadora a mediano y largo plazo. D’Ándrea y Quelch (2001:34-38) ${ }^{8}$ recomiendan que, para lograr una posición exportadora perdurable en el tiempo, es de vital importancia recurrir a las $3 \mathrm{C}$ : calidad, continuidad y confiabilidad. Además, desarrollan puntos relevantes como la definición de las ventajas competitivas, el conocimiento profundo de la estructura interna, la selección de mercado, entre otros puntos, los cuales se aplicarán en el presente proyecto.

\subsection{Objetivo general}

Analizar los factores determinantes para que Estudio Demaro brinde servicios de diseño e identidad corporativa en el mercado internacional.

\footnotetext{
${ }^{4}$ Pierini Adrián (Argentina). Exportación de Servicios de Diseño. (6 de agosto de 2012). Conglomerado de Diseño de Uruguay, [CDU MVD]. DUY 2012 - Conferencia 1er Evento anual de Diseño organizado por la Cámara y el Conglomerado de Diseño de Uruguay. Recuperado 15 de enero de 2013 de http://www.youtube.com/watch?v=_rT5tUwM9UY

${ }^{5}$ Fuentes , R..(2005). La Práctica del Diseño Gráfico. Barcelona: Paidós.

${ }^{6}$ Chaves Norberto. (s.f). La última generación en la identidad corporativa. Recuperado el 10 de diciembre de 2013 de http://www.norbertochaves.com/articulos/texto/la_ultima generacion_en la identidad_corporativa

${ }^{7}$ Estudio Demaro. Identidad y Comunicación. (2014). Recuperado 6 de junio de 2014 de http/www.estudiodemaro.com

${ }^{8}$ D'Ándrea ,G.y Quelch, J.. (2001). Marketing Estratégico en Latinoamérica: Casos de Estudio. (1ra Edición). Buenos Aires: Pearson Education.
} 
EXPORTACIÓN DE SERVICIOS DE DISEÑO E IDENTIDAD CORPORATIVA DESDE EL ESTUDIO DEMARO

\subsection{Objetivos específicos}

1. Estudiar las variables de la exportación de servicios.

2. Analizar al diseño y la identidad corporativa como servicios a exportar.

3. Elaborar un plan de marketing para que Estudio Demaro penetre en el mercado latinoamericano como empresa exportadora.

\subsection{Metodología}

Se realizará un tipo de investigación descriptiva para conocer en profundidad el contexto actual de la exportación de servicios y definir los requisitos para que Estudio Demaro la lleve a cabo.

Por un lado, se recurrirá a fuentes primarias, realizando entrevistas basadas en preguntas disparadoras al director general de Estudio Demaro, para definir con qué perfil se posiciona el estudio como empresa exportadora de servicios de diseño e identidad corporativa.

Por otro, se emplearán fuentes secundarias que otorgan datos cuantitativos y estadísticos sobre la expansión de la exportación de servicios en Argentina a través de organismos internacionales, como el Banco Mundial y la Organización Mundial de Comercio (OMC), y nacionales como la Cámara de Comercio Argentina.

Además de informes de entidades públicas y privadas reconocidas acerca del contexto, las variables de la exportación de servicios y las características de las empresas exportadoras de los mismos, siendo de utilidad para desglosar los parámetros que son imprescindibles para comercializar servicios internacionalmente a largo plazo.

Asimismo, se complementará con medios de comunicación especializados que cuentan con información sobre casos análogos existentes en el mercado y así analizar cómo es el funcionamiento del modelo de negocio.

Por último, se hará uso de bibliografía referente a la identidad corporativa, la marca y el diseño para enmarcarlos como servicios exportables.

Con dicha metodología de investigación se recopilará información que servirá como base para la elaboración del Plan de Marketing para que Estudio Demaro exporte servicios de diseño e identidad corporativa. 
EXPORTACIÓN DE SERVICIOS DE DISEÑO E IDENTIDAD CORPORATIVA DESDE EL ESTUDIO DEMARO

\section{Capítulo 1. Exportación de Servicios}

En el presente capítulo se desarrollará una descripción de las variables que comprenden a la exportación de servicios, desde los diferenciales que poseen respecto de la exportación de bienes hasta su marco legal y regulatorio. Definiendo los modos posibles de provisión de servicios, haciendo especial hincapié en el rol de los servicios profesionales concernientes a la temática de este proyecto.

Asimismo, se abordará el contexto actual de la exportación de servicios a nivel mundial; luego regional (América Latina); para después adentrarnos en Argentina como país exportador de servicios. Indagaremos sobre los rasgos del perfil nacional exportador de servicios junto a sus destinos frecuentes y/o recomendados. Para luego concluir en un análisis FODA sobre el contexto actual y cómo se para Argentina frente a él.

\subsection{Concepto de servicios}

Para hablar de la exportación de servicios se requiere, en primera instancia, hacer foco en las características de estos últimos, ya que en ellas residen las grandes diferencias respecto de la exportación de bienes.

Los servicios, como bien lo define Philip Kotler (1993: 514) ${ }^{9}$, son intangibles, y pueden o no tener relación con una representación física. La cualidad de intangibilidad le otorga a los servicios un carácter particular desde su concepción. Cada detalle de la actividad, al no ser vista, escuchada, olida, tocada o degustada antes del momento de la transacción, provoca cierta incertidumbre en los consumidores. La cual se despeja a través de la experiencia de compra del servicio. Ésta sucede en un lugar particular lleno de estímulos, mediante determinada infraestructura, con ciertas piezas de comunicación y principalmente con un equipo de personas que lo representan; conformando una percepción de calidad ligada a convertir ese intangible en tangible a través de las sensaciones generadas al momento de la transacción.

\footnotetext{
${ }^{9}$ Kotler, P. (1987). Fundamentos de Mercadotecnia.México: Prentice Hall.
} 
EXPORTACIÓN DE SERVICIOS DE DISEÑO E IDENTIDAD CORPORATIVA DESDE EL ESTUDIO DEMARO

Si pensáramos en el tipo de servicio que concierne a dicho proyecto, el servicio a brindar se hace tangible en cada acción que genera el estudio de diseño sobre el trabajo a desarrollar; desde la forma de concertación de una reunión inicial, pasando por el proceso de abordaje del diseño, hasta la forma de presentación del proyecto al cliente. Por ello es importante comprender que la calidad percibida del servicio se construye mediante percepciones vividas a cada instante y en cada suceso con llegada directa o indirecta al consumidor.

Asimismo, como mencionan Zeithalm y Bitner $(2002)^{10}$, la presencia de personas al brindar los servicios provoca que éstos no se otorguen dos veces de la misma manera, hablando así de una cualidad de heterogeneidad inherente. En comparación, los bienes logran ser estandarizados y uniformes, mientras que los servicios pueden desplegar un proceso similar en cada transacción; sin embargo, el factor humano siempre da su toque único e irrepetible.

El resto de las características que diferencian a los servicios de los bienes son: la inseparabilidad y su carácter perecedero. El primero refiere a la relación entre la producción y el consumo del servicio, en la mayoría de los casos se da en el mismo momento físicoespacial o al menos siempre están presentes ambas acciones aunque sea de manera remota. Respecto a la imperdurabilidad, se habla de la imposibilidad de almacenar servicios como ocurre con los productos físicos; no existen inventarios ni stocks.

Las particularidades antes detalladas son relevantes para planificar una plan de marketing de servicios; pudiendo influir claramente en las decisiones estratégicas a implementar en el mix de marketing. Tener presente las diferencias y los puntos de encuentro con el comercio de bienes nos permitirá planificar un plan de acción acertado a largo plazo.

\subsection{Concepto y marco legal de la exportación de servicios}

La exportación de servicios se encuentra enmarcada en el Acuerdo General de Servicios $\left(\right.$ GATS,2014) ${ }^{11}$, que entró en vigor en enero de 1995 como resultado de la Ronda Uruguay. Dicho acuerdo está avalado por los 160 miembros de la Organización Mundial de Comercio al día de la fecha, el cual afirma que se inspiró en el Acuerdo del comercio de bienes para

\footnotetext{
${ }^{10}$ Zeithaml, V. y Bitner, M.J. (2002). Marketing de Servicios, Un enfoque de integración del cliente a la empresa. México: McGraw-Hill.

${ }^{11}$ WTO.(2014).Acuerdo General de Servicios, Organización Mundial de Comercio. Recuperado 9 de diciembre de 2013 de http://www.wto.org/spanish/tratop_s/serv_s/gatsqa_s.htm
} 
EXPORTACIÓN DE SERVICIOS DE DISEÑO E IDENTIDAD CORPORATIVA DESDE EL ESTUDIO DEMARO

establecer un sistema confiable de normas comerciales internacionales para promover el comercio y su desarrollo.

EI AGCS define en el artículo I, como los definimos en el marco teórico, los cuatro modos de transferencia de servicios. A nivel mundial la mayoría de las transacciones de servicios suceden mediante el comercio transfronterizo.

\subsection{La exportación de servicios en el mundo}

Como lo define el Banco Mundial ${ }^{12}$ (2013) las exportaciones de servicios, que representan el valor de todos los servicios de mercado prestados al resto del mundo; actualmente han aumentado su protagonismo en el comercio global. La Comisión Económica para América Latina y el Caribe (CEPAL, 2009) ${ }^{13}$ sostiene que se estima que el $25 \%$ actual de las transacciones mundiales de servicios aumentará en un futuro cercano al $50 \%$.

Este cambio que habla del nivel de transabilidad de los servicios posee varias causas interrelacionadas. Por un lado, las nuevas tecnologías y las innovaciones técnicas han permitido "acortar" distancias. Por otro, el fenómeno llamado "desfragmentación" de las cadenas de valor o deslocalización de las grandes empresas o empresas trasnacionales ha permitido que actividades desarrolladas internamente comiencen a darse de forma externa.

Dentro de este panorama los servicios se encuentran integrados a este proceso de fragmentación internacional de la producción, el cual ha dado surgimiento a las cadenas globales de valor. Éstas se componen de una secuencia de etapas que comprenden desde el nacimiento del servicio hasta su comercialización. Permitiendo entonces en ciertos casos que cada etapa pueda realizarse de manera independiente y externa.

En este contexto, se habla entonces de sectores de servicios que difieren de los tradicionales servicios de turismo y transporte que históricamente dominan la composición del sector, se refieren a actividades como educación, salud pública, publicidad, investigación y desarrollo, entre otras. Asimismo, ocurre que otros rubros ya posicionados en el mercado internacional profundizaron su internacionalización; como la ingeniería y la construcción. Por

\footnotetext{
${ }^{12}$ Banco Mundial (2013). Exportaciones de Bienes y Servicios. Recuperado 17 de junio de 2014 de http://datos.bancomundial.org/indicador/NE.EXP.GNFS.ZS

${ }^{13}$ Comisión Económica para América Latina y el Caribe (CEPAL). (2009). Las exportaciones de servicios de América Latina y su integración en las cadenas globales de valor. Naciones Unidas. Santiago de Chile. Recuperado 5 de diciembre de 2013 de http://www.eclac.org/publicaciones/xml/3/35963/DocW37fin.pdf
} 
EXPORTACIÓN DE SERVICIOS DE DISEÑO E IDENTIDAD CORPORATIVA DESDE EL ESTUDIO DEMARO

último, muchas industrias consideradas “jóvenes”, como es el caso de las tecnologías de la información (TICS), juegan tempranamente un rol clave en el comercio internacional. Estos servicios con nuevo perfil exportador no sólo demuestran aumento en su participación, sino que evidencian marcadas expectativas de expansión.

Para analizar el fenómeno del comercio de servicios debemos mencionar transformaciones y acontecimientos que lo impactaron. CEPAL (2009) ${ }^{14}$ los menciona en su estudio: las tecnologías de la información; la globalización y su incidencia en la competencia de los mercados; la homogeneización de las prácticas de consumo; los procesos de reorganización empresarial que llevaron a fomentar las prácticas de tercerización (outsourcing); la integración de países que disponen de altos índices de mano de obra, como por ejemplo India; los cambios regulatorios y su consiguiente apertura de la economía. Sucesos macro que entrecruzados impactaron en la evolución de la internacionalización de servicios.

La realidad hoy acerca de la exportación de servicios es que el grueso de las transacciones se realiza entre países desarrollados. Sin embargo, economías en transición y países en desarrollo (países asiáticos y latinoamericanos) están penetrando en el mercado mundial como alternativas interesantes para captar inversiones ofreciendo en primera instancia recursos calificados a bajo costo.

La exportación de servicios presenta oportunidades atractivas, por ello hay que tener presente que la mayor parte del mundo es "competencia". Tanto por tener los mismos intereses como por desarrollar ventajas respecto de la aplicación activa de políticas gubernamentales de apoyo a la actividad, propicias legislaciones laborales, impositivas y de tratamiento a la inversión. Es necesario entonces elaborar estrategias destinadas a potenciar las condiciones favorables para adentrarse en la exportación de servicios; y desarrollar estrategias que trasciendan las ventajas transitorias relacionadas a los bajos costos.

\subsection{Las estadísticas mundiales de los comercios de servicios y su} composición: los nuevos sectores dinámicos

Respecto a las estadísticas del comercio de servicios existe cierta incertidumbre respecto a las tasas reales de crecimiento que se debe principalmente a la mencionada naturaleza

\footnotetext{
${ }^{14}$ Comisión Económica para América Latina y el Caribe (CEPAL). (2009). Las exportaciones de servicios de América Latina y su integración en las cadenas globales de valor. Naciones Unidas. Santiago de Chile. Recuperado 5 de diciembre de 2013 de http://www.eclac.org/publicaciones/xml/3/35963/DocW37fin.pdf
} 
EXPORTACIÓN DE SERVICIOS DE DISEÑO E IDENTIDAD CORPORATIVA DESDE EL ESTUDIO DEMARO

intangible de los servicios, que dificulta el registro de las operaciones; las actividades muy nuevas que no tienen definido una forma regulada de medición; los diferentes modos de provisión no son captados de la misma manera, surgiendo datos de fuentes múltiples.

El siguiente gráfico estadístico da cuenta del crecimiento ininterrumpido del comercio de servicios, con un aumento paulatino en la última década. Con mayor detalle se observa que la categoría "Otros Servicios" denota el alza más considerable de la composición general.

\section{World trade in commercial services by category, 2011}

\begin{tabular}{|c|c|c|c|c|c|c|}
\hline & \multirow{2}{*}{$\begin{array}{l}\text { Value } \\
2011\end{array}$} & \multicolumn{5}{|c|}{ Share } \\
\hline & & 2000 & 2005 & 2009 & 2010 & 2011 \\
\hline \multicolumn{7}{|l|}{ Exports } \\
\hline All commercial services & 4170 & 100,0 & 100,0 & 100,0 & 100,0 & 100,0 \\
\hline Travel & 1065 & 32,1 & 27,7 & 25,5 & 25,2 & 25,6 \\
\hline Other commercial services & 2240 & 44,8 & 49,6 & 54,4 & 53,7 & 53,7 \\
\hline \multicolumn{7}{|l|}{ Imports } \\
\hline All commercial services & 3955 & 100,0 & 100,0 & 100,0 & 100,0 & 100,0 \\
\hline Transportation services & 1100 & 28,7 & 28,8 & 25,4 & 27,3 & 27,9 \\
\hline Travel & 950 & 29,9 & 27,0 & 24,4 & 24,1 & 24,0 \\
\hline
\end{tabular}

Fuente: OMC (2011).

El análisis de las estadísticas nos permiten hacer referencia a los diferentes componentes de los servicios en general, la $5^{\mathrm{a}}$ edición del Manual de Balanza de Pagos del FMI $(2004)^{15}$, los desglosa de la siguiente manera:

“Transporte, Viajes, Servicios de Comunicación, Servicios de Construcción, Servicios de Seguro, Servicios Financieros, Servicios de Computación e Información, Regalías y licencias, Otros Servicios Empresariales, Servicios Personales, Culturales y Recreativos y Servicios de Gobierno"

Resulta necesario adentrarse en la composición de los mismos puesto que actualmente se observa una reorientación del comercio mundial de sectores tradicionales de servicios hacia nuevos sectores, este dinamismo comercial se atribuye a la categoría mencionada "Otros

\footnotetext{
${ }^{15}$ Fondo Monetario Internacional. (2004) Manual de Balanza de Pagos. 5ta edición. Recuperado el 2 de septiembre de 2014 de http://www.imf.org/external/np/sta/bop/pdf/esl/aos.pdf
} 
EXPORTACIÓN DE SERVICIOS DE DISEÑO E IDENTIDAD CORPORATIVA DESDE EL ESTUDIO DEMARO

Servicios Empresariales". Ésta abarca muchas áreas y profesiones; a pesar de ser actores muy heterogéneos se los nombra como las nuevas dinámicas en las exportaciones de servicios. Caracterizándolas de acuerdo a los denominadores comunes que comparten: uso de TICS; recursos humanos de alta calificación; baja inversión en capital físico; y su relación con las empresas trasnacionales (su rol debe tenerse en cuenta ya que de una u otra forma dominan las cadenas de valor).

Estadísticamente Red Mercosur $(2010)^{16}$ en su estudio afirma que el segmento de «otros servicios empresariales» acrecentó su contribución en el agregado de las exportaciones mundiales de servicios, pasando del $22,5 \%$ en 2000 al $25 \%$ en 2006.

\subsection{La exportación de servicios en América Latina.}

Iniciamos afirmando que es muy importante el rol que desempeñan las exportaciones de servicios en los países en desarrollo, además de generar mayor valor agregado que las exportaciones de bienes; constituyen, como lo sostiene ALES (Asociación Latinoamericana de Exportadores de Servicios (2014) ${ }^{17}$, una gran oportunidad de lograr la inserción internacional sustentada en recursos humanos altamente calificados, infraestructura y tecnología de calidad.

El estudio realizado Red Mercosur $(2010)^{18}$ menciona que en América Latina tanto exportación como importación de servicios aumentaron a un ritmo cercano a la media global. Sin embargo, agrega que el peso relativo de la región en los mercados globales es todavía pequeño, presentando la región en su conjunto un constante saldo comercial deficitario. (Ver Anexo I).

\footnotetext{
16 Red Mercosur. (2010). La Exportación De Servicios en América Latina: Los Casos de Argentina, Brasil y México. Uruguay. Recuperado 17 de junio de 2014 de http://www.redmercosur.org/la-exportacion-deservicios-en-america-latina-los-casos-de-argentina-brasil-y-mexico/publicacion/170/es/tem_12/

${ }^{17}$ Asociación Latinoamericana de Exportadores de Servicios (2014). Recuperado 6 de junio de 2014 http/www.ales-lac.org

${ }^{18}$ Red Mercosur. (2010). La Exportación De Servicios en América Latina: Los Casos de Argentina, Brasil y México. Uruguay. Recuperado 17 de junio de 2014 de http://www.redmercosur.org/la-exportacion-deservicios-en-america-latina-los-casos-de-argentina-brasil-y-mexico/publicacion/170/es/tem_12/
} 
EXPORTACIÓN DE SERVICIOS DE DISEÑO E IDENTIDAD CORPORATIVA DESDE EL ESTUDIO DEMARO

Comercio internacional de servicios por regiones 2006

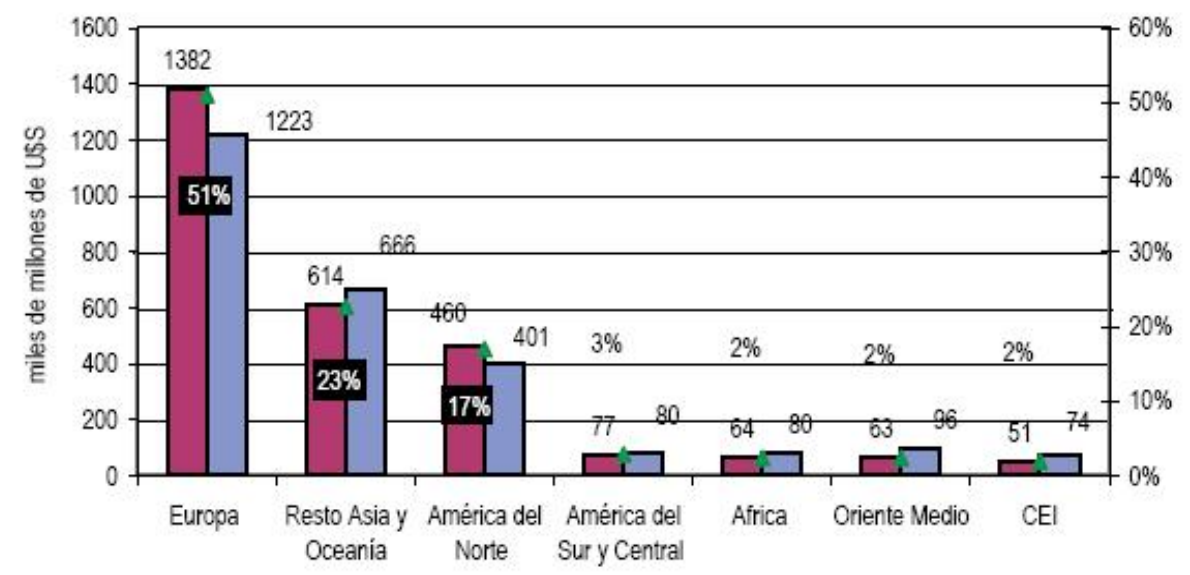

DExportaciones $\square$ Importaciones $\Delta$ Participación en el comercio mundial de servicios (eje derecho)

Fuente: elaboración propia con datos de la base estadistica de la OMC

Fuente: Santisteban (2009).

La región latinoamericana presenta un perfil de composición de exportaciones que difiere mucho del mundial. Su principal porcentaje responde a los servicios tradicionales (viajes y transporte) y presenta una menor participación en los nuevos sectores dinámicos. Sin embargo, como sostiene Santisteban $(2009)^{19}$ se dan grandes disparidades, por lo cual hay ciertos países, como Brasil, Argentina y Chile, que se despegan ampliamente del resto. Estudios estadísticos de las exportaciones del 2008 analizados por Red Mercosur (2010) detectan que:

"Brasil, Argentina y Chile tienen un papel preponderante: en 2008 explicaron el 84\% de las exportaciones de la región, siendo Brasil el exportador más importante con casi el $60 \%$ de estas transacciones."

El cuadro que precede muestra a los actores principales dentro de América Latina en servicios: Brasil lidera junto a México, y Argentina, Chile y Colombia los secundan. Respecto al peso de los nuevos sectores dinámicos (NSD) en el mismo estudio antes citado Red

${ }^{19}$ Santisteban Pérez, Diego. (3 de Diciembre de 2008). Presentación General Exportación de Servicios Síntesis Plan Piloto SIC\&PYME-BID 1206 Deloitte. V Simposio sobre Comercio Exterior e Integración “Exportación de servicios. Un nuevo desafío". Consejo Profesional de Ciencias Económicas de la Ciudad Autónoma de Buenos Aires. Recuperado 9 de junio de http://www.consejo.org.ar/congresos/5comexint.htm\#mat

${ }^{20}$ Red Mercosur. (2010). La Exportación De Servicios en América Latina: Los Casos de Argentina, Brasil y México. Uruguay. Recuperado 17 de junio de 2014 de http://www.redmercosur.org/la-exportacion-de-servicios-enamerica-latina-los-casos-de-argentina-brasil-y-mexico/publicacion/170/es/tem_12/ 
EXPORTACIÓN DE SERVICIOS DE DISEÑO E IDENTIDAD CORPORATIVA DESDE EL ESTUDIO DEMARO

Mercosur (2010) $)^{21}$ menciona que Brasil y Argentina poseen a los NSD con un rol importante en su estructura exportadora. Deslizando también la presencia de Colombia y Chile con tasas de crecimiento superiores a la media regional. (Ver Anexo II),

\section{Principales exportadores de servicios de América Latina en el año 2000 y en el 2008}

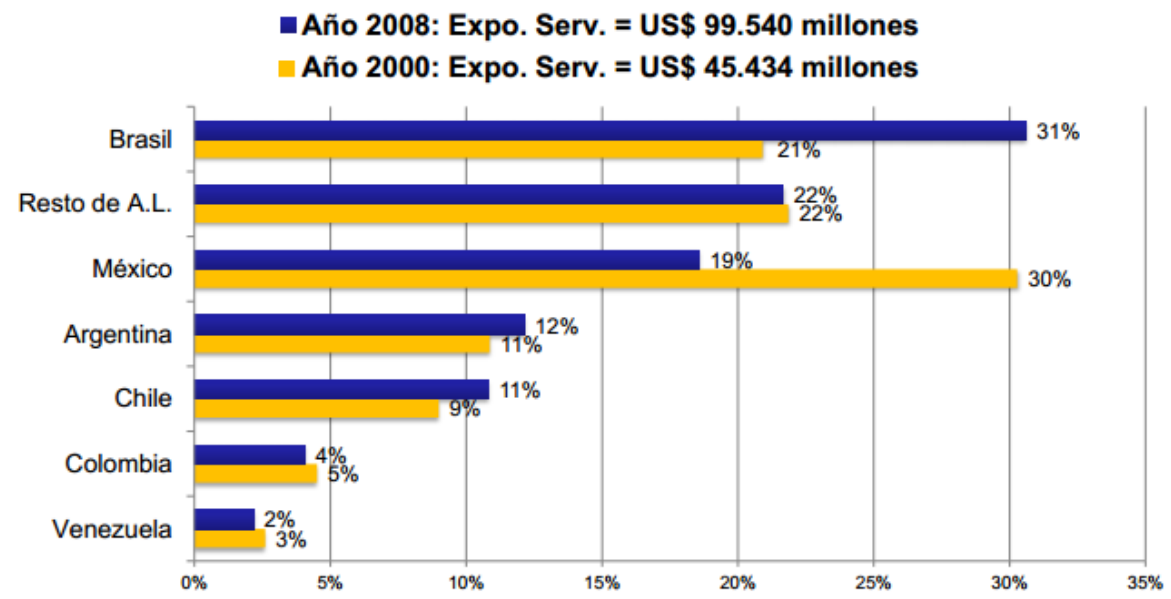

Fuente: Fundación Exportar.

La exportación de servicios desde países de América Latina se caracteriza por: un costo bajo en contraposición a los países desarrollados y recursos con calificación intelectual media-alta sumada a un muy buen nivel de creatividad y adaptación. Otro factor importante positivo es la afinidad cultural que poseen los países latinoamericanos con Estados Unidos y Europa, tanto por cercanía geográfica y horaria como por ciertos usos y costumbres.

En conclusión, podemos sostener que a nivel mundial América Latina es considerada una alternativa a la hora de deslocalizar servicios. Conformando, como afirman la Cámara Argentina de Comercio (2014) $)^{22}$ y ALES, una plataforma de servicios globales emergentes, que debe hacer hincapié en desarrollar las herramientas necesarias tanto a nivel de

\footnotetext{
${ }^{21}$ Red Mercosur. (2010). La Exportación De Servicios en América Latina: Los Casos de Argentina, Brasil y México. Uruguay. Recuperado 17 de junio de 2014 de http://www.redmercosur.org/la-exportacion-de-servicios-enamerica-latina-los-casos-de-argentina-brasil-y-mexico/publicacion/170/es/tem 12/

${ }^{22}$ Cámara Argentina de Comercio.(Mayo de 2013). Comercio Exterior de Servicios. Evolución y performance en 2012. Departamento de Economía. Recuperado 5 de diciembre de 2013 de http://app.kontakti.com.ar/data/mimgs/39_Informe\%20COMEX\%20Servicios\%202013.pdf
} 
EXPORTACIÓN DE SERVICIOS DE DISEÑO E IDENTIDAD CORPORATIVA DESDE EL ESTUDIO DEMARO

medición estadística como regulatorio para obtener datos concretos que hacen a su competitividad y así poder potenciar su perfil exportador.

\subsection{La exportación de servicios en Argentina y su promoción}

Para analizar a la Argentina como país exportador de servicios, primero debemos dar cuenta que el dinamismo que presenta en su perfil responde en primera medida a un fenómeno mundial. Actualmente en la Argentina la exportación de servicios tiene un papel activo, presentando a pesar de una balanza comercial negativa, un crecimiento constante. (Ver Anexo III).

En línea con lo que sucede a nivel regional respecto a la composición de las exportaciones, en el país se observa una clara preponderancia de la categoría "Otros Servicios", según Fundación Exportar ${ }^{23}$ (Octubre, 2013) los servicios comerciales son el 16\% del total de exportaciones argentinas en 2012. Mientras que profundizando en los servicios que integran dicha categoría, se detecta un alto porcentaje alejado del resto perteneciente a los servicios empresariales, profesionales y técnicos. (Ver Anexo IV).

Asimismo, tanto la Cámara Argentina de Comercio como la Fundación Exportar reconocen en sus análisis estadísticos que la participación de Argentina en el comercio global de servicios registra un paulatino incremento y demuestra una tendencia decreciente del déficit del Balance de Servicios del país. Mostrando además actualmente una expansión en las exportaciones de servicios no tradicionales. (Ver Anexo V).

\section{Evolución positiva de las exportaciones} argentinas de servicios (US\$ millones)

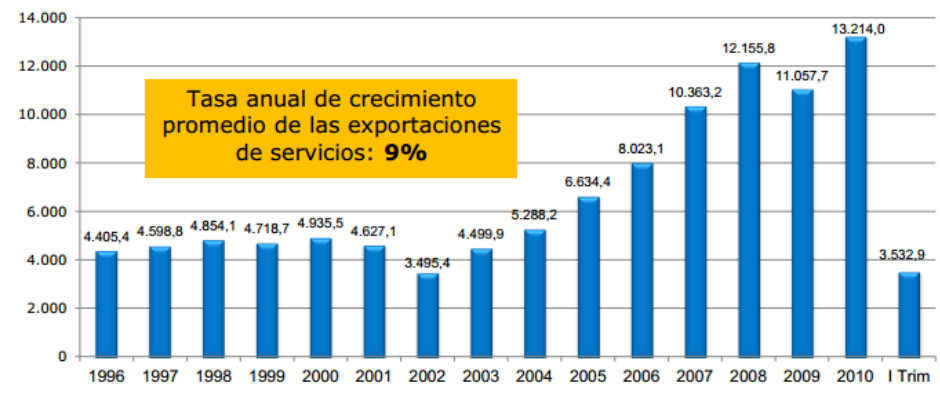

Fuente: Fundación Exportar.

\footnotetext{
${ }^{23}$ Fundación Exportar, (Octubre 2013). La exportación de servicios comerciales argentinos. Recuperado 7 de septiembre de 2014 de http://www.outsource2lac.com/documents/PPT_2013_sobre_Las_Exportaciones_de_Servicios_de_Argentinaweb.pdf
} 
EXPORTACIÓN DE SERVICIOS DE DISEÑO E IDENTIDAD CORPORATIVA DESDE EL ESTUDIO DEMARO

Según el informe de la Fundación Exportar ${ }^{24}$ actualmente Argentina se encuentra en el puesto $44^{\circ}$ de países exportadores de servicios del mundo, detrás de México (puesto $43^{\circ}$ ) y Brasil (puesto $30^{\circ}$ ) en la región, y delante del resto de las economías latinoamericanas. Específicamente en el área que nos concierne en este proyecto: sector diseño, según las estadísticas comparativas que podemos obtener del SRIAM ${ }^{25}$ entre los años 2000 y 2012 , Argentina es el tercer país del ranking superado por México y Brasil.

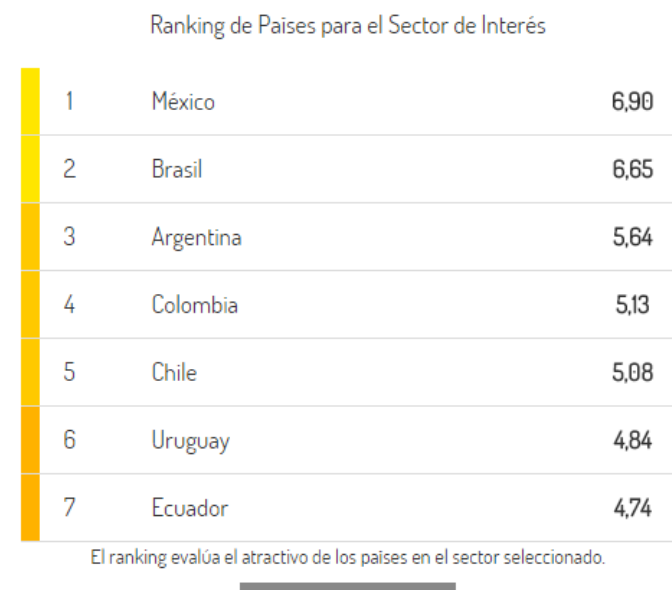

Fuente: Sistema Regional Armonizado (2014), Asociación Latinoamericana de Exportadores de Servicios.

La transformación del sector productivo, es decir, el proceso hacia una economía con mayor peso en el sector servicios, viene ocurriendo hace más de tres décadas. Países desarrollados como Italia, Alemania y Japón, que poseían hace treinta años similar participación a la Argentina en la actividad terciaria, hoy generan con ella el $70 \%$ del valor agregado de sus economías. ${ }^{26}$ Si lo tomamos como referencia podemos proyectar la evolución de nuestro país.

\footnotetext{
${ }^{24}$ Fundación Exportar, (Octubre 2013). La exportación de servicios comerciales argentinos. Recuperado 7 de septiembre de 2014 de http://www.outsource2lac.com/documents/PPT 2013 sobre Las Exportaciones de Servicios de Argentinaweb.pdf

${ }^{25}$ SRIAM, Sistema Regional I Armonizado (2014), Asociación Latinoamericana de Exportadores de Servicios, http://ales-lac.org/sriam/index.php/site

${ }^{26}$ Cámara Argentina de Comercio. (Noviembre 2010). El Rol del Sector Servicios en Argentina. Departamento de Economía. Recuperado el 10 de septiembre de http://www.cac.com.ar/documentos/59_relevancia\%20del\%20sector\%202011.pdf
} 
EXPORTACIÓN DE SERVICIOS DE DISEÑO E IDENTIDAD CORPORATIVA DESDE EL ESTUDIO DEMARO

El desarrollo de políticas públicas para el posicionamiento y desarrollo de las exportaciones de servicios es esencial para el país. Destacaremos dos iniciativas de promoción del tema que nos concierne. Un sistema regional armonizado (SRIAM) ${ }^{27}$, desarrollado por ALES en alianza con la Cámara Argentina de Comercio y con el apoyo del Banco Interamericano de Desarrollo (BID). Una plataforma online que brinda información calificada para profesionalizar y cuantificar el comercio de servicios y así poder acceder a datos que permitan fomentar las inversiones y las exportaciones del sector. Detectando los factores de localización que se tienen en cuenta tanto por exportadores, importadores e inversores. Lo cual permite trabajar dichos puntos de forma transversal y específica de cada subsector (arquitectura, publicidad, animación digital, diseño, entre otros) y generando análisis comparativos entre países de la región.

La Fundación Exportar, una institución mixta que se dedica a la promoción comercial dependiente del Ministerio de Relaciones Exteriores y Culto, cuya misión es fomentar el incremento y la diversificación de las exportaciones argentinas; presenta un amplio accionar en promoción de servicios, llevando a cabo misiones comerciales y presencia en ferias de sectores específicos.

En conclusión, debe existir un fuerte accionar del Estado para lograr posicionarse como país exportador de servicios. Tanto a nivel regional como en el país se halla un fuerte impulso para profundizar el perfil exportador de servicios. Sin embargo, se debería pautar una agenda oficial que potencie estas circunstancias para generar información de calidad y ventajas competitivas para lograr que la estrategia sea efectiva y sostenible en el tiempo.

\subsection{Argentina marca país}

Conocer el perfil de Argentina como país en el contexto mundial es primordial para poder posicionarse como empresa argentina exportadora. El Banco Mundial ${ }^{28}$ sostiene que Argentina es una de las economías más grandes de América Latina, con un PBI de US $\$ 490.000$ millones. En el perfil regional, evidencia buenas relaciones con la mayoría de países que lo conforman, formando parte de organismos de integración y bloques económicos como Mercosur, Aladi y UNASUR, cumpliendo en ellos un rol activo. El país es

\footnotetext{
${ }^{27}$ Sistema Regional de Información y Armonización Metodológica.(2014). Recuperado 6 de junio de 2014 http://ales-lac.org/sriam/index.php/site

${ }^{28}$ Banco Mundial (2013). Argentina. Recuperado 17 de junio de 2014 de http://datos.bancomundial.org/pais/argentina
} 
EXPORTACIÓN DE SERVICIOS DE DISEÑO E IDENTIDAD CORPORATIVA DESDE EL ESTUDIO DEMARO

uno de los principales productores de materias primas con su agricultura y ganadería vacuna y uno de los mayores exportadores de carne del mundo. Según el Banco Mundial la apertura del mercado de China representa un impulso en la consolidación de un perfil exportador. Además de experimentar el último tiempo un récord de crecimiento en la industria nacional, en particular en los sectores automotriz, textil, y de electrodomésticos.

Acudimos al informe de Fundación $\operatorname{Exportar~}^{29}$ que da datos de posicionamiento internacional: “-Entre los 144 países considerados en el Ranking de Competitividad Global 20122013 del World Economic Forum, la Argentina integra el grupo de las 21 economías en transición hacia el último grupo de las 35 economías guiadas por la innovación, entre las que se encuentran las economías más avanzadas del planeta.

-En el Informe sobre Desarrollo Humano 2013 de Naciones Unidas titulado: "EI ascenso del Sur: Progreso humano en un mundo diverso", la Argentina figura en el puesto $45^{\circ}$ del índice de 186 países, dentro del grupo de países con IDH Muy Alto que integran mayormente los países desarrollados.

-Argentina aparece también en el puesto $30^{\circ}$ del A.T. Kearney Global Services Location Index 2011 que encabeza la India seguida por China y Malasia."

Es importante analizar lo que connota Argentina en el resto del mundo, lo que se da a llamar marca país. Un análisis de la consultora Future Brand ${ }^{30}$ (2013) sobre la imagen país en Latinoamérica, coloca a Argentina en el segundo lugar del ranking detrás de Brasil respecto a 21 países. (Ver Anexo VI). El "Country Brand Index Latinoamérica" pondera a las marcas país respecto a las asociaciones que éstas generan en las personas a partir de evaluar cinco dimensiones. Respecto de ellas Argentina posee niveles altos en los indicadores "Calidad de Vida" y "Turismo". Mientras que posee un nivel intermedio de posición en "Sistema de Valores". Y sus niveles bajos responden a "Aptitud para hacer Negocios" y "Patrimonio y Cultura".

\footnotetext{
${ }^{29}$ Fundación Exportar, (Octubre 2013). La exportación de servicios comerciales argentinos. Recuperado 7 de septiembre de 2014 de http://www.outsource2lac.com/documents/PPT_2013 sobre_Las Exportaciones de_Servicios de_Argentinaweb.pdf

${ }^{30}$ Future Brand (2013). Country Index Latinoamérica 2013, Extraído de http://www.futurebrand.com/images/uploads/studies/cbi/CBI_Latinoamerica_2013_Espanol.pdf
} 
EXPORTACIÓN DE SERVICIOS DE DISEÑO E IDENTIDAD CORPORATIVA DESDE EL ESTUDIO DEMARO

Lo antes desarrollado demuestra que Argentina es un país con grandes expectativas y oportunidades y brinda un panorama general, al cual debemos prestar especial atención en el diseño del plan de ingreso a otros países, pudiendo definir cuáles aspectos debemos potenciar dando indicios de cómo delinear el perfil de presentación empresarial.

\subsection{EI mercado meta y las PyMEs en la exportación argentina de servicios}

En nuestro país los destinos actuales de las exportaciones son, según la Cámara Argentina de Comercio: el Mercosur, Brasil como principal socio comercial; la Unión Europea y Asia y le sigue el NAFTA. Detectando un alto índice de comercio interregional de servicios.

Para seleccionar estratégicamente un destino para las exportaciones de servicios que nos concierne, en principio, debemos recalcar que el proyecto involucra a una PyME: Estudio Demaro. Ello va a ser un aspecto determinante a la hora de seleccionar el mercado meta al cual penetrar. La denominación PyME según define la Fundación Observatorio Pyme ${ }^{31}(2013)$ refiere a: "una unidad económica, dirigida por su propietario de forma personalizada y autónoma, de pequeña dimensión en cuanto a número de trabajadores y cobertura de mercado". Se da siempre una estrecha relación entre el tamaño de la empresa, su cantidad de empleados, su nivel de formalidad y su desarrollo organizativo.

Hoy, las pymes son consideradas un interesante sector para motivar su grado de internacionalización, ya que poseen un marcado potencial de crecimiento. Las condiciones que da la globalización del comercio produjeron un cambio en las ventajas comparativas entre las grandes y pequeñas empresas. Éstas últimas, si establecieron alianzas estratégicas, están en condiciones de crecer a nivel internacional.

Por otro lado, debemos tener en cuenta varios factores a la hora de definir un mercado meta, como menciona CEDEX $(2014)^{32}$, se recomienda para las empresas pequeñas y medianas que recién se inician en la exportación de servicios regionalizar sus actividades; logrando en

\footnotetext{
${ }^{31}$ Fundación Observatorio PyME. (Abril de 2013). Informe Especial: Definiciones de PyME en Argentina y el resto del mundo. Recuperado 17 de junio de 2014 de http://www.observatoriopyme.org.ar/download/informes/IE_Definicion_PyME-FOP-Abril_2013.pdf

${ }^{32}$ CEDEX (Centro de Estudios para el Desarrollo Exportador), (s.f) Las pymes y su rol en el comercio internacional, Universidad de Palermo. Extraído el 3 de agosto de 2014 de http://www.palermo.edu/cedex/pdf/pyme_com_internacionall.pdf
} 
EXPORTACIÓN DE SERVICIOS DE DISEÑO E IDENTIDAD CORPORATIVA DESDE EL ESTUDIO DEMARO

primera instancia adquirir conocimiento acerca del funcionamiento del negocio y generando una adaptación al mercado con mayor cautela y proyección. Asimismo, apuntar en primera instancia a la región "cercana", tanto a nivel físico como a nivel cultural, permite al empresario pyme hacer un análisis directo de sus fortalezas y debilidades como exportador. Santiesteban (2009) ${ }^{33}$ revela en su investigación que el principal destino de los servicios de nuestro país hoy es América Latina, siendo un factor determinante la red de contactos que se genere. Existe un enorme potencial de las pymes de servicios talento-intensivas dentro de la dinámica de la globalización y el paradigma de la economía del conocimiento. Todos puntos de partida que nos permitirán delinear acciones del plan de marketing.

\subsection{Análisis FODA de Argentina como exportador de servicios}

Para dar cierre a este capítulo, haremos un análisis FODA de Argentina como exportador de servicios, dando cuenta de los diferentes aspectos antes desarrollados y detectando que factores pueden incidir positiva o negativamente al desarrollo del proyecto en cuestión. Haremos alusión a distintas fuentes especialistas en el tema para concluir detallando aspectos a potenciar para desarrollar el perfil exportador de Estudio Demaro.

\section{Fortalezas}

- Disponibilidad de servicios y técnicas de calidad no viables en ciertos países de la región. La penetración de Internet en Argentina (65,5\% de la población) es comparable a la de los países desarrollados. ${ }^{34}$

- Reconocimiento y empatía a nivel latinoamericano del perfil intelectual y académico de los profesionales argentinos.

- Alta valoración de los publicistas argentinos en la industria a nivel mundial.

- Existencia de planes estratégicos para la promoción de distintos sectores como el software, el turismo, entre otros.

\footnotetext{
${ }^{33}$ Santisteban Pérez, Diego. (3 de Diciembre de 2008). Presentación General Exportación de Servicios Síntesis Plan Piloto SIC\&PYME-BID 1206 Deloitte. V Simposio sobre Comercio Exterior e Integración "Exportación de servicios. Un nuevo desafío". Consejo Profesional de Ciencias Económicas de la Ciudad Autónoma de Buenos Aires. Recuperado 9 de junio de http://www.consejo.org.ar/congresos/5comexint.htm\#mat

${ }^{34}$ Fundación Exportar, (Octubre 2013). La exportación de servicios comerciales argentinos. Recuperado 7 de septiembre de 2014 de http://www.outsource2lac.com/documents/PPT_2013_sobre_Las_Exportaciones_de_Servicios_de_Argentinaweb.pdf
} 
- Recursos humanos calificados.

- Huso horario conveniente respecto a otras regiones, lo que se denomina nearshoring (brecha física cercana con E.E.U.U., principal país demandante de servicios).

- Importantes centros urbanos.

- Afinidad cultural con mercados potenciales (a nivel regional y además con E.E.U.U y determinados países de la Unión Europea como España).

- Perfil empresario creativo e innovador. ${ }^{35}$

- Habla hispana.

\section{Debilidades}

- $\quad$ Alto grado de informalidad del sector servicios en nuestro país, especialmente en subsectores como Servicios profesionales, Audiovisuales y Diseño ${ }^{36}$.

- Falta de promoción nacional de las exportaciones de servicios e inexistencia de un marco normativo nacional específico para la promoción.

- Se utilizan 'certificaciones de calidad' en pocas empresas argentinas exportadoras.

- Subestimación del valor real de las exportaciones argentinas de servicios debido a la metodología de registro actualmente empleada.

- Inexistencia de un estudio sobre la potencialidad exportadora del sector servicios a nivel nacional.

- La legislación argentina relativa a los 'consorcios de exportación' no facilita a las empresas que los integran una rápida recuperación del IVA.

\section{Amenazas}

- Inestabilidad macro económica

- Percepciones negativas de imagen país en el extranjero en determinados aspectos.

- $\quad$ Cargas impositivas elevadas. ${ }^{37}$

${ }^{35}$ Cámara Argentina de Comercio de Estados Unidos en Argentina (2009). Exportación de Servicios, oportunidades de crecimiento para la Argentina. Recuperado 4 de septiembre de 2014 de http://www.amchamar.com.ar/cms/files/492//regionalizacion\%20de\%20servicios\%2002032009.pdf

${ }^{36}$ Centro de Implementación de Políticas Públicas para la Equidad y el Crecimiento (CIPPEC). (Marzo 2011). Anatomía de las empresas exportadoras de servicios de la Ciudad Autónoma de Buenos Aires. Documento de Trabajo N61, Recuperado 5 de diciembre de 2013 de http://www.cippec.org/documents/10179/51827/61+DT+IGyDP,\%20Anatom\%C3\%ADa+de+las+empresa s+exportadoras+de+servicios+de+la+Ciudad+Aut\%C3\%B3noma+de+Buenos+Aires, \%20Castro, \%20Ferr aro,\%202011.pdf/9314e18e-291e-4cba-b500-671285e361eb

${ }^{37}$ Santisteban Pérez, Diego. (3 de Diciembre de 2008). Presentación General Exportación de Servicios Síntesis Plan Piloto SIC\&PYME-BID 1206 Deloitte. V Simposio sobre Comercio Exterior e Integración "Exportación de servicios. Un nuevo desafío". Consejo Profesional de Ciencias Económicas de la Ciudad Autónoma de Buenos Aires. Recuperado 9 de junio de http://www.consejo.org.ar/congresos/5comexint.htm\#mat 
EXPORTACIÓN DE SERVICIOS DE DISEÑO E IDENTIDAD CORPORATIVA DESDE EL ESTUDIO DEMARO

- Aprobación de legislación específica para la promoción de las exportaciones de servicios en otros países de la región (por ejemplo: en Perú).

- Ventajas impositivas y crediticias para exportadores de servicios en otros países de la región. ${ }^{38}$

- A través de organismos internacionales (OMC,UNCTAD), otros países de la región han estudiado el potencial de su exportación de servicios.

- Mejores condiciones laborales para ciertos profesionales argentinos en el exterior favorecen la fuga de capital humano.

- Falta de información sobre mercados de destino.

- Falta de aliados estratégicos.

- Insuficiente acceso al financiamiento.

- Falta estructura de comercio exterior.

- Restricciones para el establecimiento de empresas en países extranjeros.

\section{Oportunidades}

- Nuevas tecnologías de transmisión para, por ejemplo, las operaciones bancarias electrónicas y los servicios de telesanidad o de teleeducación.

- Reformas normativas en sectores antes con estricta reglamentación.

- Envejecimiento de la estructura poblacional de los países desarrollados.

- Expectativa de crecimiento del comercio internacional de servicios en el comercio mundial del $20 \%$ al $50 \%{ }^{39}$.

- 50 millones de población hispana en E.E.U.U.

- Estratos poblacionales con alto poder adquisitivo en Centro y Sudamérica.

- Horizonte de la economía mundial 2020: análisis sectorial da cuenta de la necesidad de puestos con media y alta cualificación en servicios ${ }^{40}$.

\footnotetext{
${ }^{38}$ CEPAL,(2013) Perspectivas económicas de América Latina 2013. Extraído 1 de octubre de 2013 de http://www.cepal.org/es/publicaciones/1463-perspectivas-economicas-de-america-latina-2013-politicas-de-pymespara-el-cambio

${ }^{39}$ Fundación Exportar, (Octubre 2013). La exportación de servicios comerciales argentinos. Recuperado 7 de septiembre de 2014 de http://www.outsource2lac.com/documents/PPT_2013_sobre_Las_Exportaciones_de_Servicios_de_Argentinaweb.pdf

${ }^{40}$ Fundación Exportar, (Octubre 2013). La exportación de servicios comerciales argentinos. Recuperado 7 de septiembre de 2014 de http://www.outsource2lac.com/documents/PPT_2013_sobre_Las_Exportaciones_de_Servicios_de_Argentinaweb.pdf
} 
EXPORTACIÓN DE SERVICIOS DE DISEÑO E IDENTIDAD CORPORATIVA DESDE EL ESTUDIO DEMARO

- Alto posicionamiento del sector publicidad y subcontratación de varias etapas de la producción de las piezas publicitarias: creación, diseño, producción, distribución ${ }^{41}$.

- Argentina como el país de mayor tasa de crecimiento de las exportaciones de servicios 2002-2007 entre los países integrantes de ALADI.

- Tipo de cambio favorable.

- Fomento del uso del diseño y las industrias creativas.

En el FODA podemos evidenciar que existen debilidades en las cuales se debe prestar especial atención para contrarrestarlas, principalmente las referentes a la falta de un accionar macro para el fomento de las exportaciones de servicios: información estratégica, financiamiento y estructura de comercio exterior tanto pública como privada. Por otro, la amenaza del avance de otros países latinoamericanos que ya están realizando acciones de posicionamiento en el área.

Potenciar las oportunidades dan cuenta de estar preparados para poder captar ese amplio crecimiento que va a tener el sector, el cual demandará no sólo recursos humanos calificados e infraestructura de calidad sino el aporte innovador y creativo del perfil de empresa para destacarse entre el caudal de alternativas. El énfasis en las fortalezas del perfil exportador argentino debe centrarse para el proyecto en cuestión en la reputación de los profesionales y la fuerza de trabajo, con claras ventajas del subsector publicidad.

En referencia al mercado de destino podemos recomendar que inicialmente $E D^{42}$ inicie su experiencia exportadora en la región, apuntando a los países en que se encuentra mejor posicionado. Tomando como referencia a los líderes regionales: México y Brasil y apuntando a dar respuesta a los factores que los inversionistas de su rubro evalúan a la hora de la localización internacional.

\footnotetext{
${ }^{41}$ Pellandra Andrea (2008). El Comercio de Servicios en los países de ALADI: Perfiles, patrón exportador y casos exitosos. Oficial de Asuntos Económicos de la División de Comercio Internacional e Integración. Recuperado 5 de septiembre de http://www.cepal.org/comercio/noticias/paginas/9/34499/04_Andrea_Pellandra.pdf

${ }^{42}$ Estudio Demaro. Identidad y Comunicación. (2014). Recuperado 6 de junio de 2014 de http/www.estudiodemaro.com
} 


\subsection{Conclusiones.}

De todo lo desarrollado podemos ver la situación actual de la exportación de servicios en nuestro país, desde la mirada positiva: emergente y con potencial; y desde la cara opuesta: incertidumbre y desinformación. Por ello, ED al iniciarse como empresa exportadora debe abocarse profundamente a los requisitos necesarios para posicionarse a mediano y largo plazo: definir su oferta exportable, conocer su mercado meta, generar intercambio y contacto con los organismos de promoción, profundizar su red de contactos y potenciar las fortalezas de su sector.

La oportunidad de ED, de dar sus primeros pasos en el comercio internacional de servicios le genera beneficios para trascender el mercado local, y a su vez, posicionarse en el mismo con una imagen global que repercutirá en su calidad y valor de proyectos. Asimismo, le permitirá mejorar sus procesos de trabajo, haciéndolos más eficientes y competitivos. 


\section{Capítulo 2. Diseño e Identidad Corporativa}

En este capítulo daremos inicio al análisis del sector que nos concierne: diseño, profundizando en los criterios específicos y transversales de la disciplina que se deben tener en cuenta para lograr un perfil exportador a mediano y largo plazo. También hablaremos sobre el rol del diseño en el contexto nacional y la mirada internacional hacia el mismo. Asimismo, se recurrirá a casos análogos de disciplinas cercanas al sector para detectar el perfil empresarial junto a los desafíos que deben atravesarse para lograr exportar servicios de manera exitosa.

\subsection{Definiciones de diseño e identidad corporativa}

Como mencionamos anteriormente en el marco teórico acontece un cambio de paradigma respecto a lo que hoy se considera diseño e identidad corporativa. Actualmente el diseño ya no se relaciona directamente con lo meramente visual sino que posee un respaldo estratégico indiscutible. El Centro Metropolitano de Diseño (CMD) ${ }^{43}$ lo define como pensamiento proyectual (design thinking) y no lo asocia directamente a la estética. Roberto Fuentes ${ }^{44}$ afirma que el diseño gráfico es un vehículo de información. Mientras que respecto a la identidad corporativa o de marca Aaker ${ }^{45}$ menciona que ésta es compleja puesto que se integra por un conjunto de asociaciones que se establecen con el público objetivo mediante una propuesta de valor. Dicha propuesta implica beneficios funcionales, emocionales o de autoexpresión. En otras palabras, la identidad no se reduce a la marca visual sino que se construye alrededor de un universo identitario tangible e intangible que comunica.

\section{Como afirma Norberto Chaves ${ }^{46}(2012)$ :}

\footnotetext{
${ }^{43}$ CMD, Centro Metropolitano de Diseño. Offengedeen Camila, Bracuto Verona Guadalupe, Sanguinetti Marcos. (2011). Aportes del diseño, Una herramienta para mejorar el desempeño empresarial. Ministerio de Desarrollo Económico

${ }^{44}$ Fuentes Roberto.(2005). La Práctica del Diseño Gráfico, Barcelona: Paidós.

${ }^{45}$ Aaker David, Joachimstaler, E. (2005). Liderazgo de marca. Buenos Aires: Deusto.

${ }^{46}$ Chaves Norberto. (s.f). La última generación en la identidad corporativa. Recuperado 10 de diciembre de 2013 de http://www.norbertochaves.com/articulos/texto/la_ultima_generacion_en la identidad_corporativa
} 
EXPORTACIÓN DE SERVICIOS DE DISEÑO E IDENTIDAD CORPORATIVA DESDE EL ESTUDIO DEMARO

"se dio un ascenso de la identidad del nivel táctico al estratégico. No sólo se diseña la identidad sino que se gestiona".

ED se encuentra en el nivel que dicho autor denomina "la 3er etapa de la identidad corporativa" la cual comprende la generación del marketing estratégico y el posicionamiento corporativo. Se diseña a partir de definiciones estratégicas y de un diagnóstico de situación de la empresa y/o institución.

Actualmente además del diseño se habla de varias disciplinas, que agrupadas se dan a llamar "industrias creativas". La Conferencia sobre las Naciones Unidas sobre Comercio y Desarrollo (UNCTAD, 2008) ${ }^{47}$ las define como aquellas actividades que se generan combinando tres grandes ámbitos: arte/cultura, empresa/innovación, ciencia/tecnología. Se caracterizan por tener como principal insumo al capital intelectual, asociado siempre a la creatividad. Hoy las industrias creativas son: los productos audiovisuales, el diseño, los nuevos medios informativos, las artes del espectáculo, la edición y las artes visuales. Unesco $^{48}$ y el programa de Naciones Unidas para el Desarrollo (PNUD) en su informe sobre la Economía Creativa, afirman que las industrias creativas impulsan las economías y el desarrollo. Además amplían acerca del aporte que trasciende el mero valor monetario, y que refiere que las industrias creativas generan contribución al desarrollo social sostenible y al diálogo intercultural, es decir, poniendo a las personas en el centro de la escena.

\subsection{El valor del diseño y su significación para las empresas globales}

Particularmente hoy hay cierto desconocimiento por parte de las empresas de lo que puede producir el diseño, se debe arraigar la creencia de que el diseño claramente mejora la performance empresarial y/o institucional. Evidenciar el valor estratégico del diseño es condición para lograr posicionarlo como servicio exportable, dándolo a conocer como una herramienta que incrementa la competitividad de las empresas.

\footnotetext{
${ }^{47}$ UNCTAD, PNUD, “Economía Creativa: Una opción factible de Desarrollo", Informe 2010, extraído de http://unctad.org/es/Docs/ditctab20103_sp.pdf el 27 de agosto de 2013.

${ }^{48}$ UNESCO,(2013), extraído de http://www.unesco.org/new/es/media-services/in-focus-articles/creative-industriesboost-economies-and-development-shows-un-report/
} 
EXPORTACIÓN DE SERVICIOS DE DISEÑO E IDENTIDAD CORPORATIVA DESDE EL ESTUDIO DEMARO

El valor agregado que el diseño aporta a las empresas es la mayoría de las veces intangible; sin embargo en el último tiempo cobró mayor atención gracias a la globalización. Dando a conocer las acciones de las multinacionales y los primeros casos de éxito en diseño de las medianas y pequeñas empresas. Como sostiene Pierini ${ }^{49}$ :

“La globalización permite unificar criterios estratégicos de producción, comunicación e implementación sin dejar de lado los valores aspiracionales y costumbres propios de cada cultura".

Ello promovió la idea de comercializar servicios por fuera de los límites nacionales y penetrar en mercados de otros países a través de disciplinas creativas.

El diseño tiene una gran cualidad subyacente que es el análisis simbólico y el análisis de contexto que realiza sobre las empresas, permitiendo resignificar los conocimientos de acuerdo a las necesidades de éstas. Como sostiene la diseñadora industrial Beatriz Galán ${ }^{50}$ :

"el pensamiento proyectual vincula a las empresas con las ideas-valor que sostienen las comunidades, las incorpora y las vuelca en las externalidades de la empresa, les da visibilidad y lo traduce en los patrones de la economía globalizada".

El campo de acción del diseño es muy amplio y abarcativo, mencionaremos algunos ejemplos de cómo puede aplicarse la disciplina a la oferta de distintos servicios: diseño de productos, diseño de imagen e identidad corporativa (servicio que ofrece Estudio Demaro), diseño de packaging y embalaje, diseño de stands y mobiliario comercial, diseño de material promocional (folletería, merchandising), diseño editorial, diseño digital, multimedial y web, consultoría de diseño estratégico. Todas las actividades mencionadas poseen la capacidad de impactar de forma positiva tanto en materia productiva como comercial de las empresas/ productos.

En el informe Aportes del Diseño ${ }^{51}$ se aborda un estudio cualitativo de casos múltiples de empresas que incorporaron servicios de diseño, dando cuenta del aporte desde una

\footnotetext{
49 Pierini Adrián.(2011). Diseño for export: La nueva tendencia proyectual creativa. Recuperado 6 de junio de 2014 de http://www.pierinipartners.com/material-pedagogico.php

${ }^{50}$ CMD, Centro Metropolitano de Diseño. Offengedeen Camila, Bracuto Verona Guadalupe, Sanguinetti Marcos. (2011). Aportes del diseño, Una herramienta para mejorar el desempeño empresarial. Ministerio de Desarrollo Económico

${ }^{51}$ CMD. Offengedeen Camila, Bracuto Verona Guadalupe, Sanguinetti Marcos. (2011). Aportes del diseño, Una herramienta para mejorar el desempeño empresarial. Ministerio de Desarrollo Económico
} 
EXPORTACIÓN DE SERVICIOS DE DISEÑO E IDENTIDAD CORPORATIVA DESDE EL ESTUDIO DEMARO

herramienta de análisis que contempla: el nivel de innovación en una serie de variables proyectuales, y el nivel de impacto en aspectos tanto comerciales como productivos de las empresas. Encontramos allí una selección de casos que dan cuenta del valor agregado que los servicios de diseño pueden significar en los negocios, concluyendo que:

- el diseño es una herramienta capaz de mejorar el desarrollo empresarial;

- la incorporación de diseño suele ir acompañada de otras acciones estratégicas por parte de las empresas;

- $\quad$ el diseño es una herramienta aplicable, en mayor o menor medida, a todas las actividades económicas;

- el brief o encargo realizado por parte de la empresa suele ser reformulado por el equipo de diseño;

- los estudios de diseño suelen tener estructuras chicas y flexibles, que les permiten adaptarse a las necesidades particulares de cada proyecto;

- $\quad$ el diseñador transfiere a la empresa hábitos metodológicos que representan un aporte difícilmente reconocido, pero muy significativo.

Los casos reales desarrollados en dicho informe son experiencias exitosas representativas que colaboran a formar una cultura de diseño en las empresas y dan cuenta del valor estratégico del diseño para mejorar su competitividad. Fomentar estas creencias en el mercado empresarial es fundamental para posicionar el rol del diseño como servicio.

\subsection{Percepciones del diseño gráfico latinoamericano y argentino}

Según la revista Pymes ${ }^{52}$ el índice global de innovación de Argentina evidencia una gran evolución. Nuestro país se caracteriza por tener un valor inputs en niveles medio-bajo de innovación y paradójicamente outputs en niveles altos de innovación. Ello habla del grado de adaptación, creatividad en la soluciones y aprovechamiento de los recursos que posee nuestra nación. Ello es valorado en gran medida por el cliente extranjero, según testimonios del sector exportador audiovisual, Argentina se caracteriza por el talento y la capacidad de trabajo. Asimismo, hay otros aspectos en los cuales el perfil empresarial internacional difiere del nacional, como por ejemplo, en el respeto por los tiempos pautados, la organización y la prolijidad.

\footnotetext{
${ }^{52}$ Revista Pymes, Cultura Emprendedora. (Febrero 2014). Índice Global de Innovación. Nro 119. Pág. 8.
} 
EXPORTACIÓN DE SERVICIOS DE DISEÑO E IDENTIDAD CORPORATIVA DESDE EL ESTUDIO DEMARO

EI SRIAM (Sistema Regional Armonizado) ${ }^{53}$ presenta en su análisis estadístico sobre comercio exterior de servicios de diseño los siguientes criterios específicos: creatividad y cumplimiento, madurez industrial y recursos humanos; y como aspectos transversales: calidad de infraestructura, competitividad y riesgo país, plataforma de negocios, recursos humanos y estructura general de costos. Argentina denota niveles bajos en competitividad y riesgo país y estructura general de costos mientras que en recursos humanos y calidad de infraestructura se encuentra muy bien posicionado. Los mejores niveles en criterios específicos son: creatividad, recursos humanos y madurez industrial. En el orden de países latinoamericanos exportadores de servicios de diseño, como se mencionó en el capítulo anterior, Argentina se halla en el tercer puesto detrás de Brasil y México.

A nivel latinoamericano, el diseño no posee una imagen cohesiva, es decir, se presentan grandes disparidades respecto al desarrollo y calidad del servicio entre los países de Latinoamérica. No se puede hablar de un diseño latinoamericano homogéneo, sin embargo el diseñador brasilero Felipe Taborda ${ }^{54}$ sostiene en su libro Latin America Graphic Design que el diseño latinoamericano posee un modo de expresión específico. El cual está asociado a un diseño colorista y festivo que apela a su origen y valores populares transmitiendo identidad, armonía y expresión. El coautor, Julius Wiedemann, agrega que:

"El uso del color y los valores son muy distintos a como lo trabajan en otros países.

Acá la idea es combatir y revolucionar. Estamos intentando, con imágenes, literatura y con publicidad hacer una revolución. El mensaje de trasgresión es parte de nuestro ADN".

Con lo cual se están hallando estilos discursivos y formales que de una u otra manera representan el espíritu del diseño gráfico latinoamericano.

Respecto al diseño gráfico nacional, Argentina posee grandes referentes unipersonales: Ronald Shakespear, Norberto Chaves, Diego Giaccone, Jorge Frascara, entre otros. Su trayectoria y reconocimiento trasciende los límites nacionales y cada uno posee un alto grado de especialización en subdisciplinas del diseño tales como packaging, señalética, sistema de identidad, diseño de información, etc. Internacionalmente no estamos

\footnotetext{
${ }^{53}$ Sistema Regional Armonizado (SRIAM) de la Asociación Latinoamericana de Exportadores de Servicios.(s.f). Recuperado 6 de junio de 2014 http/www.ales-lac.org/sriam/

${ }^{54}$ Taborda, Felipe y Wiedemann Julius, (2008). Latin America Graphic Design, Taschen.
} 
EXPORTACIÓN DE SERVICIOS DE DISEÑO E IDENTIDAD CORPORATIVA DESDE EL ESTUDIO DEMARO

posicionados fuertemente a nivel diseño, sin embargo la realización de ideas y ejecución de publicidades consolidó al país con una percepción positiva en sus disciplinas afines: publicidad, arte, diseño, audiovisual. En el caso de la publicidad, se sacó frutos de la oportunidad generada por la crisis económica mundial y se desarrolló un ambiente laboral que fue capaz de dar respuesta a una demanda exigente y experta. De ello, debemos aprehender para construir un espacio a nivel empresarial que se consolide y no sólo funcione en casos aislados.

En cuanto al contexto académico del diseño, hay cada vez más universidades públicas y privadas, institutos terciarios, y cursos específicos que desarrollan y lo abordan como una profesión con gran potencial. En este aspecto es importante destacar que muchos jóvenes de América Latina eligen a Argentina para especializarse en diseño y carreras afines, connotando una imagen académica respetada en los países de los cuales provienen. Según el Ranking Mundial de Universidades por Temática QS $2015^{55}$,la Universidad de Buenos Aires se ubica en la elite de las instituciones universitarias por integrar el grupo de las 200 mejores entre 971 rankeadas y sobre un total de 3467 evaluadas. Las carreras de Diseño ocupan la posición 32 a nivel global resultando las mejores rankeadas entre el total de las 31 carreras de la UBA incluidas en el ranking.

A nivel estatal, se designó por UNESCO a Buenos Aires como la primera ciudad creativa; y además se creó el sello del buen diseño, el cual permite demostrar el valor agregado de estar evaluado en calidad de diseño. Calidad e innovación son las ventajas competitivas que toda pyme debe apuntar a alcanzar para diferenciarse y prolongar su competitividad a largo plazo. Esto aplica ya sea para pymes que producen como para pymes que brindan servicios.

\subsection{Casos análogos. Servicios de arquitectura. Servicios audiovisuales.}

Es enriquecedor poder relevar casos reales de exportación de servicios creativos en el país para lograr armar una "fotografía" certera acerca del accionar a activar por parte de Estudio Demaro. Se seleccionaron dos casos paradigmáticos, ya sea por su cercanía con la disciplina como por sus resultados y posicionamiento en el exterior.

\footnotetext{
${ }^{55}$ UBA, Universidad de Buenos Aires, extraído el 30 de abril de 2015 de http://www.uba.ar/comunicacion/detalle_nota.php?id=18693
} 
EXPORTACIÓN DE SERVICIOS DE DISEÑO E IDENTIDAD CORPORATIVA DESDE EL ESTUDIO DEMARO

Por un lado, el estudio de arquitectura Bórmida y Yanzón ${ }^{56}$, el cual es presentado como caso de éxito de arquitectura de exportación en la revista News ${ }^{57}$ de la Fundación Exportar.

La dupla de arquitectos se caracteriza por un alto grado de especialización, que responde a la proyección y ejecución de bodegas y espacios vitivinícolas. Respondiendo en gran medida a su lugar de procedencia: Mendoza. Su pericia les permitió ingresar de manera ininterrumpida a clientes de otros países. Su éxito responde a una alta capacidad técnica en el tema, al uso constante de metodologías de trabajo y a la versatilidad de trabajo con diferentes equipos multidisciplinarios. Sumado a ello, el estudio participa activamente de ferias y eventos internacionales que le permiten acceder a clientes específicos para ofrecer sus servicios. Además, Bórmida y Yanzón se hace presente en diferentes actividades de promoción relacionadas a su nicho de mercado junto a organismos que promueven la exportación (Fundación Exportar, Fundación Promendoza) y en eventos académicos internacionales que le permiten continuar posicionando su perfil exportador. Un rasgo relevante es la obtención de premios que es sinónimo de reconocimiento y a la vez funciona como garantía en el imaginario social de los potenciales clientes.

Por otro lado abordaremos el cine de animación o diseño audiovisual, un sector que ha crecido de manera ininterrumpida en el último tiempo, la revista Pymes ${ }^{58}$ lo define como una usina exportadora. Guarda características similares con el servicio de arquitectura antes desarrollado, que refieren al trabajo multidisciplinario, al desarrollo contínuo de herramientas existentes para trabajar a distancia (Skype, google drive, dropbox, wetransfer) y la asistencia permanente a ferias del sector (por ejemplo, Festival Internacional de Animación Expo Toons).

Mientras que se distingue a nivel estructural por su composición de estudios de pequeña o mediana envergadura, que realizan alianzas con grandes empresas para financiarse; tales son los casos de Estudio Smilehood con Disney (programa de TV El payaso Plim Plim), Estudio Mundo Loco CGI con Telefé Contenidos (película Metegol); Estudio Astrolab Motion

\footnotetext{
${ }^{56}$ Bórmida Yanzón Arquitectos, (s.f), Recuperado el 7 de abril de 2015 de http://www.bormidayanzon.com.ar

${ }^{57}$ Arquitectura de exportación. Caso Bórmida y Yanzón Arquitectos.(Octubre 2011). News. Newsletter de Fundación Exportar. 36-42. Recuperado 25 de abril de 2014 de http://www.exportar.org.ar/web2013/news.php

${ }^{58}$ Roca, Aixa. (Febrero 2014). Animación: una usina exportadora. Pymes, Cultura Emprendedora. Nro 119. 26-38.
} 
EXPORTACIÓN DE SERVICIOS DE DISEÑO E IDENTIDAD CORPORATIVA DESDE EL ESTUDIO DEMARO

con la editorial española SOL90 (serie educativa Exploradores de la Historia).Sumado a ello, aparece el rol de los profesionales freelance, un aspecto idéntico a la industria del diseño gráfico, lo cual permite a los estudios ampliar su capacidad de trabajo ante proyectos de gran envergadura. Es decir, que muchas veces el "estudio pyme" logra llevar a cabo trabajos de gran alcance gracias a su flexibilidad frente a los recursos humanos. Se arman equipos especiales respondiendo a la necesidad y tipo del proyecto. Se rescatan como atributos del perfil argentino el atrevimiento y la frescura en las historias y en cómo se aborda la disciplina; conjugando el talento, la capacidad y la gestión para lograr posicionarse como una alternativa para el exterior.

Como se hace alusión en la revista News ${ }^{59}$ de la Fundación Exportar es relevante para los estudios audiovisuales conseguir financiamiento para las producciones y evidenciar a sus clientes extranjeros que poseen respaldo institucional. Respecto a ello, actualmente a nivel promoción y apoyo del estado, la industria audiovisual es la que posee en mayor medida una asistencia financiera y asesoramiento para fomentar su desarrollo. Además de estar designada como sector estratégico, a nivel nacional se determinó un polo audiovisual lo cual genera una sinergia para concretar coproducciones y crear contenido original en el país con alto potencial exportador.

En ambos casos paradigmáticos captamos ciertos aspectos a reproducir, trasladar , homologar para la disciplina y el actor que nos concierne (servicios de diseño e identidad corporativa desde Estudio Demaro):

- la presencia en ferias del sector y afines;

- la asociatividad con otros empresas del sector;

- la asistencia y participación activa en sectores aledaños que permiten hacer contacto con futuros clientes;

- la construcción de equipos multidisciplinarios y el ingrediente de lo freelance para dar respuesta a proyectos de distinta envergadura;

- la actualización y especialización constante en materia de conocimiento específico y tendencias.

\footnotetext{
${ }^{59}$ Scornik, Verónica. (Enero 2012). Diseño de animación Caso Astrolab Motion. News. Newsletter de Fundación Exportar. 22-28. Recuperado 25 de abril de 2014 de http://www.exportar.org.ar/web2013/news.php
} 
EXPORTACIÓN DE SERVICIOS DE DISEÑO E IDENTIDAD CORPORATIVA DESDE EL ESTUDIO DEMARO

\subsection{El diseño como disciplina exportable. Estudios de diseño que exportan.}

El diseño de identidad y comunicación corporativa es una disciplina que se caracteriza por abordar rubros, temáticas, clientes y públicos diferentes en cada proyecto. Esto requiere hacer especial hincapié en un ida y vuelta profundo, activo y comprometido con cada proyecto en particular, para lograr detectar las necesidades intrínsecas y extrínsecas del cliente (empresa, institución, producto o servicio). Esta característica trasladada a un proyecto global debe enfatizarse ya que el perfil del cliente extranjero es diferente respecto del argentino. Como ya mencionamos, se respetan en mayor medida el cumplimiento de los tiempos de entrega y la organización es clave para una buena ejecución. En otras palabras, el proceso de trabajo debe estar planificado contemplando las posibles desavenencias basado en una metodología interna sólida que lo sustente.

De una búsqueda y análisis amplio de estudios de diseño argentinos exportadores, seleccionamos dos estudios de diseño con trayectoria en exportación para desarrollar brevemente su perfil y detectar características y metodologías comunes para aplicar a Estudio Demaro.

Pierini Partners ${ }^{60}$ es un estudio de gran trayectoria con clientes extranjeros, principalmente de países latinoamericanos como también Alemania, Francia, Bélgica y Estados Unidos. Se especializa dentro del diseño en packaging de productos masivos y denota un perfil altamente académico y profesional que fundamenta afirmando que sus soluciones comunicacionales se basan en comprender las idiosincrasias globales. En otras palabras, interpretar el público objetivo, sus costumbres locales y aquellas que trascienden la procedencia. Su Director General Adrián Pierini sostiene: "los países buscan proveedores más allá de las fronteras priorizando la experiencia por sobre la localización”, recomendando que la investigación y análisis previo de los mercados a penetrar es indispensable para hallar "vacíos" proyectuales y actuar en función de ellos.

Pierini detecta que hace ya un tiempo se dio un proceso unificador, en el cual los códigos gráficos se han vuelto comunes y son decodificados por la mayoría de los consumidores.

\footnotetext{
${ }^{60}$ Pierini Partners, Diseños estratégicos que impulsan sus marcas. Recuperado el 9 de abril de 2015 de www.pierinipartnes.com
} 
EXPORTACIÓN DE SERVICIOS DE DISEÑO E IDENTIDAD CORPORATIVA DESDE EL ESTUDIO DEMARO

Este proceso que viene de la mano de la globalización; hoy se potencia con el uso de las redes sociales, siendo un aspecto que debe estar presente en la estrategia de penetración a otros mercados. Podemos hablarle a un gran público trascendiendo las nacionalidades.

Por último el director de Pierini Partners agrega que para lograr el éxito en la exportación de diseño se debe apuntar a la capacidad ejecucional de alta calidad pautando de antemano los parámetros de acción: impacto, diferenciación pretendida, pluralidad comunicacional.

Desde su accionar Pierini Partners se posiciona como un aliado estratégico de los clientes dando a conocer los riesgos y beneficios de un diseño innovador y cómo puede o no maximizar ganancias.

Gorricho ${ }^{61}$ es un estudio de la ciudad de Buenos Aires que posee 12 años de trayectoria y se aboca al diseño de marcas para pymes de América y Europa. Su fundador Martín Gorricho es docente reconocido de varias universidades e instituciones, dando frecuentemente talleres y conferencias. El estudio se caracteriza por ofrecer servicios de diseño y rediseño de marca, y demás piezas gráficas. El perfil de empresas que aborda comprende principalmente negocios en crecimiento que consideran al diseño como un gran aporte para el lanzamiento, posicionamiento de la marca/ producto. Como se titula el artículo del suplemento de arquitectura Arq $^{62}$ de Clarín "el diseño que ayuda a vender", es decir, el diseño como una estrategia clave para generar mejores resultados de negocio.

En este caso, creemos relevante destacar la metodología de producción ágil que emplea su estudio. La cual comunican de forma externa, dando a conocer su proceso de trabajo y enmarcando una disciplina "subjetiva" e imaginativa como lo es el diseño en un contexto de formalidad y abordaje sistémico. Ello pone de manifiesto credibilidad y transparencia ante la mirada del cliente.

Asimismo, Gorricho Estudio de Diseño cuenta con presencia en medios locales y nacionales especializados mostrando como la dupla entre diseño y empresa se potencian y logran resultados exitosos. Los testimonios de sus clientes extranjeros ponderan la interpretación de las necesidades y de lo que se quiere comunicar como un rasgo de gran valor.

\footnotetext{
${ }^{61}$ Gorricho Estudio de Diseño, (s.f), Recuperado el día 9 de abril de 2015 de www.gorricho.com.ar 62 Suplemento de Arquitectura ARQ, Diario Clarín, 9 de septiembre de 2014.
} 
EXPORTACIÓN DE SERVICIOS DE DISEÑO E IDENTIDAD CORPORATIVA DESDE EL ESTUDIO DEMARO

En ambos casos de referencia detectamos que para los estudios de diseño que quieran penetrar a mercados internacionales son relevantes los siguientes puntos:

- el rol académico como credibilidad, reconocimiento e imagen, el desarrollo de artículos del rubro y dictado de conferencias en distintas partes del país / mundo;

- la prensa y los medios especializados como canales de difusión del sector e indirectamente de sus servicios profesionales;

- la metodología proyectual de los procesos de trabajo definida y expuesta;

- la mirada e interpretación profesional que agrega valor a la empresa o institución trascendiendo lo puramente gráfico;

\subsection{El perfil actual de Estudio Demaro a nivel local}

Estudio Demaro se caracteriza por abordar proyectos de manera integral combinando diseño, comunicación, marketing y sentido común. Su diferencial reside justamente en poder dar vida a proyectos desde una mirada que interpreta las necesidades de la empresa, apuntando siempre a soluciones que mejoren la performance en el mercado. En otras palabras, se realiza siempre previamente a la etapa gráfica una fase de consultoría, en la cual además de recabar información se genera un diálogo activo con el cliente para poder traducir sus requerimientos y delinear una estrategia. Se utilizan dos documentos para llevar registro de lo definido: brief de proyecto y propuesta de actuación. Cada uno cumple un rol activo para desarrollar el proyecto de manera viable, permitiendo dejar por escrito la fundamentación que da inicio al proceso gráfico.

La trayectoria de Estudio Demaro mencionada en el marco teórico permite destacar su versatilidad en materia de sectores y mercados en los cuales brindó sus servicios; mientras que su especialización refiere a la tipología o perfil de empresa. Con ello hablamos de empresas, instituciones o productos que miran más allá y asumen desafíos con el fin de evolucionar. Son empresas que por distintas razones se diferencian de su competencia ya sea por sus atributos disruptivos o sus decisiones de cambio y/o expansión.

Estudio Demaro cuenta con una estructura interna pequeña de entre 5 - 7 integrantes que se complementa con una red interdisciplinaria de disciplinas aledañas: arquitectura, fotografía, diseño industrial, decoración de interiores, entre otros. Actualmente posee liderazgo local y un posicionamiento como referente de los estudios de diseño de la ciudad. 
EXPORTACIÓN DE SERVICIOS DE DISEÑO E IDENTIDAD CORPORATIVA DESDE EL ESTUDIO DEMARO

\subsection{Conclusiones.}

En conclusión, en el presente capítulo podemos visualizar un panorama sobre el diseño y la identidad corporativa en nuestro país y el rol que asume frente a las empresas como oferente de servicios. Los casos paradigmáticos nos permiten interpretar los aspectos fundamentales que este tipo de disciplinas creativas deben abordar y potenciar para generar incidencia en hechos concretos del negocio. Es importante reafirmar que la asociatividad constante promovida en distintos sectores: académico, prensa, corporativo, institucional, entre otros permite crear una red de contactos fuerte, posicionarse como actor en el mercado y estar actualizado sobre el know how de la exportación de servicios de diseño. No debemos dejar de lado, la tarea de impulsar una continua y profunda construcción de una identidad latinoamericana del diseño que nos permitirá posicionarnos a largo plazo como una alternativa concreta hacia el mundo. Estudio Demaro tiene un perfil competitivo que se debe traducir en el plan de marketing para penetrar en el mercado latinoamericano. 
EXPORTACIÓN DE SERVICIOS DE DISEÑO E IDENTIDAD CORPORATIVA DESDE EL ESTUDIO DEMARO

\section{Capítulo 3. Plan de Marketing Internacional}

La fundamentación de esta tesis es demostrar que una pyme de servicios como Estudio Demaro puede exportar identidad y diseño a mediano y largo plazo, delineando un plan estratégico de marketing internacional que apunte a captar un nicho de mercado inicial en Latinoamérica para desarrollar su primera experiencia de manera exitosa.

El mercado meta decanta del análisis del capítulo 1 sobre la exportación de servicios en Argentina y de acuerdo a la teoría recabada, la cual habla de la selección de mercado en los primeros pasos de internacionalización como una herramienta de aprendizaje. Según D'Andrea y Quelch ${ }^{63}$ los destinos próximos y cercanos convienen para que la empresa reconozca y resuelva los problemas típicos que se presentan.

Entonces en el presente capítulo desarrollaremos dicho plan de marketing que tiene como principal objetivo que Estudio Demaro logre la internacionalización, teniendo como objetivo a largo plazo lograr una unidad de negocio operativa independiente dentro de la estructura actual.

\subsection{Perfil de empresa, misión y visión}

Actualmente Estudio Demaro presenta reducida experiencia internacional con casos de proyectos abiertos, en la que al momento no se pudo lograr la concreción. Específicamente dos empresas del sector maquinaria agropecuaria de Bolivia y un estudio profesional en Suecia. Se está realizando un viaje a la ciudad de Santa Cruz de la Sierra para dar inicio a los proyectos y generar un lazo con el cliente.

La misión de Estudio Demaro es integrar el diseño con otras disciplinas para mejorar la performance de las organizaciones, mediante un compromiso profundo con la cabeza

\footnotetext{
${ }^{63}$ D’Ándrea Guillermo, Quelch John. (2001).Marketing Estratégico en Latinoamérica: Casos de Estudio. ( $1^{\text {a }}$ Edición). Buenos Aires: Pearson Education.
} 
EXPORTACIÓN DE SERVICIOS DE DISEÑO E IDENTIDAD CORPORATIVA DESDE EL ESTUDIO DEMARO

(estrategia) y con el alma (intuición y pasión); la combinación justa para brindar intangibles que se hacen tangibles.

La estrategia de internacionalización de ED está alineada con su visión, enfocada en generar vínculos con empresas de otros países ofreciendo servicios con un estándar de alta calidad.

Asimismo hoy atraviesa una reestructuración que apunta a hacer un análisis de los clientes actuales, agruparlos por características en común desde el punto de vista de los desafíos que implican para poder abordarlos de manera sistémica. Se define un criterio ligado a la visión del cliente respecto de su mercado, el estudio se orienta a acompañar a empresas medianas que estén en crecimiento, reestructuración y/o que quieran asumir nuevos riesgos o desafíos comerciales.

A nivel capacidad instalada el estudio cuenta con 5 máquinas marca Apple, internet banda ancha de 12 megas, dropbox empresarial y herramientas como skype, teléfonos móviles y de línea para generar un contacto fluido con el exterior. Su equipo de trabajo se compone de especialistas universitarios en cada área de servicios que ofrece: identidad, comunicación, web y audiovisual.

Actualmente ED (Estudio Demaro) presenta un nivel de compromiso alto con el desarrollo del presente objetivo y plan de marketing, buscando potenciar la filosofía de la empresa: acompañar a las empresas en sus procesos dándole una mirada comercial al abordaje de diseño y comunicación. El estilo de dirección de la empresa se caracteriza por ser colaborativo, horizontal y de intercambio, cada rol cumple una función específica y a la vez se atraviesan para poder construir una visión macro e interrelacionada.

El sector del diseño como desarrollamos en el capítulo anterior no se encuentra totalmente posicionado como servicio exportable pero si forma parte de un conjunto de disciplinas y profesiones que están explotando sus capacidades y talento, como lo es el mercado audiovisual. Asimismo, detectamos un estadio en el cual las pequeñas y medianas empresas comienzan a asumir que el diseño es un servicio que mejora la performance de la empresa. Esta creencia es clave y se debe promover tanto en el discurso externo como interno puesto que ED sostiene fehacientemente que sus servicios logran impactar de lleno en la realidad y el futuro de las empresas. 


\subsection{Objetivo general y objetivos específicos del Plan de Marketing}

El objetivo principal del plan de marketing a desarrollar es que Estudio Demaro trascendia el mercado doméstico en una primera etapa de 8 a 12 meses obteniendo de 2 a 4 unidades de clientes de similares características en 2 o más países latinoamericanos tales como: Bolivia, Perú, Colombia y/o Ecuador.

En la siguiente etapa comprendida de 6 a 12 meses, la meta es generar un carácter de continuidad en las exportaciones que signifiquen la internacionalización de los servicios brindados comprendiendo el $20 \%$ sobre las ventas totales del Estudio con una cartera de clientes activa.

Como objetivos específicos y secundarios se busca el aumento de rentabilidad de la empresa, la obtención de mayor status/ prestigio por las exportaciones realizadas que significarán potenciar el liderazgo local generando imagen de marca como estrategia de expansión del negocio. Asimismo se considera relevante el aprehender el know how operativo diario afinando los procesos informativos y proyectuales internos.

A largo plazo se busca que la internacionalización de los servicios funcione como una unidad de negocio del estudio independiente del mercado local aunque utilice la misma estructura operativa, compartiendo recursos humanos.

\subsection{Estrategia del Plan de Marketing}

En primera instancia el nivel de implicación definido es el regrocentrismo ${ }^{64}$ definido como aquel que visualiza el comercio exterior como un conjunto de países con aspectos y características similares aplicando entonces la misma estrategia.

\footnotetext{
${ }^{64}$ Presentación (2013). Marketing Internacional en Mercados Internacionales, Universidad Nacional de La Plata. Profesora Dra. Cristina Zapata
} 
EXPORTACIÓN DE SERVICIOS DE DISEÑO E IDENTIDAD CORPORATIVA DESDE EL ESTUDIO DEMARO

Respecto a la estrategia de mercado se aplicará un criterio de concentración el cual refiere a enfocar el esfuerzo y los recursos a una cantidad reducida de servicios y de mercados, logrando una especialización en ellos que permita una relación a largo plazo.

La estrategia inicial será penetrar desde el perfil del estudio, el cual se destaca por un estilo de gestión confiable y distendido en donde las decisiones se toman en conjunto con los clientes. Generando sinergia entre el know how del rubro y los conocimientos de diseño, comunicación y marketing. ED es una empresa que entra en el nuevo paradigma ${ }^{65}$ esto implica que aborda su accionar diario con foco en la flexibilidad y hace especial hincapié en la cultura organizacional interna.

Respecto a los servicios definidos a ofrecer: identidad, comunicación, web y audiovisual; la idea es posicionar al estudio como referente argentino que se identifique por:

-la mirada global que combina lo comercial, la visión y lo intangible para darle un valor agregado a lo que la empresa necesita;

-el estilo discursivo y estético "fresco y espontáneo" siempre guardando relación con el tipo de empresa o institución.

La ventaja competitiva que brinda Estudio Demaro es la consultoría. Ésta se halla incluida en cada servicio ofrecido, lo cual se aplica en todo el proceso de definiciones del proyecto en cuestión. Por ejemplo ED mediante la escucha activa e interpretación de lo expuesto por el cliente plantea ¿se necesita un rediseño de marca o en realidad se requiere de una campaña publicitaria para darse a conocer con la marca existente?... se interpela la necesidad del cliente para descubrir la necesidad real. No se realizan piezas gráficas o estéticas aisladas, sino comunicación que aporta a la imagen y competitividad de la empresa.

Asimismo, ED a través de un documento entregable: la propuesta de actuación, traduce la situación de la empresa para definir la comunicación visual que se requiere en el caso en particular. Resaltar la experiencia que posee en situaciones de crisis, es decir, potenciar el perfil nacional que connota que las empresas argentinas se destacan por haber pasado crisis

\footnotetext{
${ }^{65}$ Presentación (2013). Administración Estratégica de la Firma, Universidad Nacional de La Plata. Profesor José Pagano.
} 
EXPORTACIÓN DE SERVICIOS DE DISEÑO E IDENTIDAD CORPORATIVA DESDE EL ESTUDIO DEMARO

económicas, salir fortalecidos o encontrar la manera de pivotear (cambiar la estrategia, foco o función) se utiliza como fortaleza para posicionar al estudio en su proceso de internacionalización.

La estrategia cierra con el foco la tipología de empresa a la cual se le brinda servicio: pymes que no pueden acceder a los carísimos grandes estudios, un segmento que suele recibir poca atención y que representa una gran oportunidad. Dar respuesta y acompañamiento a las pymes en crecimiento un segmento relegado por los grandes estudios de diseño y agencias de publicidad que apuntan sólo a las multinacionales.

\subsection{Segmentación y mercado meta.}

Respecto a la selección de mercados se apunta a un grupo de países latinoamericanos homogéneos o que presenten similitudes en cuanto a la necesidad del servicio. El mercado meta serán las pymes latinoamericanas que busquen tener una imagen global y que necesiten invertir en posicionar su marca o producto. Hoy las pymes en América Latina son consideradas como potenciales agentes de cambio. Interpretar sus necesidades actuales para lograrlo y poder dar respuesta mediante el diseño y la comunicación otorgándoles visibilidad mediante una imagen de calidad, sostenible en el tiempo.

En primera instancia, se potenciará un aspecto existente al momento del desarrollo del presente plan, el desarrollo de dos proyectos en la ciudad de Santa Cruz de la Sierra, Bolivia. Se detectó que las empresas del país en cuestión que hoy en día quieren actualizar su imagen y le dan relevancia al diseño e identidad son aquellas que exportan, es decir, que necesitan generar contacto hacia fuera con el mundo. Comunicar un perfil global y sólido, reformulando sus estrategias de posicionamiento.

Bolivia posee como país tres centros urbanos y de consumo importantes: La Paz, Santa Cruz de la Sierra y Cochabamba. Su economía ha crecido sostenidamente en los últimos veinte años y el PBI registra un aumento anual. El Sistema Integrado de Información de Comercio Exterior de Perú en el desarrollo de la Guía de Mercado de Bolivia ${ }^{66}$ sostiene que su actividad económica fundamental es la explotación de hidrocarburos (gas y petróleo). Por

\footnotetext{
${ }^{66}$ Sistema Integrado de Información de Comercio Exterior de Perú, Guía de Mercado de Bolivia. Extraído 14 de mayo de 2015 http://www.siicex.gob.pe/siicex/resources/fichapais/1001064218RADE9EE4.PDF
} 
EXPORTACIÓN DE SERVICIOS DE DISEÑO E IDENTIDAD CORPORATIVA DESDE EL ESTUDIO DEMARO

ello los bienes y servicios que exporta mayormente responden al gas natural, zinc, metales preciosos, aceite crudo de petróleo entre otros. Asimismo tiene un gran segmento que exporta frutas frescas y frutos secos. El estado boliviano es miembro de la mayoría de organizaciones internacionales en materia económica y de comercio internacional. Según el Banco Mundial ${ }^{67}$ Argentina es uno de sus principales proveedores de hidrocarburos.

En la mayoría de los países latinoamericanos, como en Bolivia, las relaciones personales son altamente valoradas. Generalmente en primera instancia se produce el conocimiento de la persona para luego llegar a concretar un negocio, es decir, es de suma importancia el primer contacto para generar relaciones interpersonales positivas. Se debe tener muy en cuenta que la cultura boliviana se caracteriza por ser formal en las relaciones de negocios, no logran confianza en tiempos cortos y no otorgan información relevante de su negocio en el primer encuentro. Latinoamérica se caracteriza por tener un amplio margen en la negociación al momento de la concreción del negocio; buscando siempre altos beneficios pero otorgando concesiones a medida que trascurre la negociación. ${ }^{68}$

En conclusión, y en concordancia con análisis estadísticos y contextuales de capítulos anteriores, la definición del segmento a dirigirse refiere a pymes latinoamericanas para las cuales Argentina sea una alternativa accesible y reconocida por su versatilidad ante situaciones adversas y talento creativo en las disciplinas pertinentes.

\subsection{Mezcla del Plan de Marketing: Servicios. (Producto)}

Como estrategia de servicio se recurrirá a la expansión geográfica - enfoque etnográfico, el cual refiere a la doble expasión de servicio y comunicación. Los servicios brindados por ED son: identidad, comunicación, audiovisual y web. Cada uno de ellos puede funcionar de manera individual o entrecruzarse en proyectos integrales. Es necesario igualmente definirlos desde el perfil de ED para profundizar su diferenciación.

Identidad. ED piensa las marcas como sistemas de identidad integrales que deben articularse en distintos medios y sostener los valores de la empresa, producto $u$ organización. Haciendo hincapié en lo que las marcas tienen para contar. Construyendo un

\footnotetext{
${ }^{67}$ Banco Mundial, (2015), http://www.bancomundial.org/es/country/bolivia/overview\#1

${ }^{68}$ Material académico curso online (2015), Internacionalización de la empresa, Connect to Americas. https://academy.connectamericas.com/en/web//internacionalizacion-de-la-empresa-4-edicion
} 
EXPORTACIÓN DE SERVICIOS DE DISEÑO E IDENTIDAD CORPORATIVA DESDE EL ESTUDIO DEMARO

relato único e irrepetible: tono de voz, personalidad y espíritu. Ese relato es el que genera un vínculo con el exterior y da a conocer las marcas con su público objetivo.

Comunicación. Se define junto al cliente a quién le quiere hablar la marca, empresa o institución para establecer lineamientos de comunicación y lograr un diálogo fluido e innovador. Se desarrollan ideas en base a un proceso creativo, un análisis profundo de la temática y un gran compromiso con el discurso comunicacional que traspasa lo conocido. Se buscan nuevas formas de hablarle a las personas, tocando sus fibras internas.

Web. Se aborda a partir de conocer las necesidades de los usuarios. Se hace especial hincapié en el diseño de sitios simples, atractivos y fáciles de navegar que logran empatía entre los clientes y la empresa, institución, marca o producto. Se determinan los tipos de sitio posibles en relación a la realidad del comitente, con un análisis que define qué tipología le resulta más conveniente según sus objetivos comerciales.

Audiovisual. Es un servicio amplio que permite a través de todos los recursos audiovisuales disponibles comunicar de manera impactante desde el lanzamiento de un producto hasta la presentación corporativa de una empresa. Se generan piezas comunicacionales que se caracterizan por el dinamismo, lo conceptual y el desarrollo de contenido. Se abordan necesidades que van más allá de la gráfica estática requiriendo especial foco en el proceso creativo de guion y armado de story board.

Cada uno de los servicios descriptos son unidades dirigidas por especialistas que forman equipos de trabajo a medida de cada proyecto caracterizándose por lo interdisciplinario y la consultoría como un diferencial claro que impacta de lleno en los resultados de posicionamiento de marca.

\subsection{Precio.}

En cuanto a la estrategia de precios se definirá un precio de marketing orientado al mercado, con relación a un precio de referencia manejado en el contexto. Asimismo, se llevarán a cabo estrategias específicas de acuerdo al servicio, al tamaño de la empresa y a los requerimientos del proyecto que concluirán en precios múltiples. 
EXPORTACIÓN DE SERVICIOS DE DISEÑO E IDENTIDAD CORPORATIVA DESDE EL ESTUDIO DEMARO

Se realizó una búsqueda incipiente sobre presupuestos de distintos perfiles de estudios de diseño de Latinoamérica y España para encontrar un rango de valores respecto a los servicios que ED ofrece (ver Anexo VII). Ello nos permite definir un precio por encima de la media para posicionarnos de la mano del valor agregado del servicio.

La definición de la política de precios ${ }^{69}$ mantendrá una coherencia interna y externa, donde el precio y el valor percibido se relacionen, teniendo en cuenta las percepciones del cliente asociadas a una imagen de calidad.

\subsection{Distribución (Plaza)}

En lo referente a la estrategia de canal, delineamos varias puertas de entrada para la penetración. En primera medida contactos e intermediarios especialistas en marketing internacional en los países en cuestión. Tener un referente en cada zona para lograr la credibilidad y confianza del cliente por medio de "distribuidores" de los servicios de ED.

En este punto, es esencial hacer hincapié en la formación de cultura organizacional para lograr transmitir desde el inicio el perfil diferencial del estudio y que funcionen de manera externa pero con el espíritu de pertenecer a un estudio creativo que trabaja de manera proactiva para alcanzar las metas y objetivos de cada proyecto.

Por otro lado, el contacto con instituciones, organismos y empresas mediante el envío de mailing corporativos y contacto personal por medio electrónicos a cargo de la directora del área de marketing internacional.

En el siguiente punto se definirá mediante el mix de comunicación distintas pautas que repercutirán también en la forma de entrada para la internacionalización de servicios de ED.

\subsection{Comunicación (Promoción)}

El mix de comunicación se potencia en este caso en particular por ser un estudio de diseño y comunicación con experiencia en la generación de campañas publicitarias, esto debe ser una fortaleza a aprovechar al máximo para planificar un mix con llegada y alcance al público

\footnotetext{
${ }^{69}$ Presentación (2012). Estrategias y políticas de Precio, Universidad Nacional de La Plata. Profesor Alberto Albarellos.
} 
EXPORTACIÓN DE SERVICIOS DE DISEÑO E IDENTIDAD CORPORATIVA DESDE EL ESTUDIO DEMARO

objetivo mediante publicidad y trade marketing. Se define una estrategia push, en la cual el esfuerzo se concentra directamente en el consumidor final del servicio.

ED cuenta con un sitio web actual en el cual se pueden navegar y conocer todos los servicios con casos reales, la promoción del mismo como sustento del perfil corporativo es clave para mostrarse solventes y sólidos. Asimismo, posee desarrollado un brochure digital e impreso que permite utilizarlo de carta de presentación. Este punto entonces hará sinergia con los siguientes puntos del mix de comunicación que tienen como objetivo lograr un posicionamiento en el corto plazo de ED como Estudio Argentino de Diseño en Latinoamérica.

La presencia online en las redes sociales en general: facebook, twitter y específicas o cercanas al rubro como pinterest y behance; significa tener abiertos varios canales de llegada e interacción con el público objetivo y con el mercado en general. Estar al tanto y "seguir" a los estudios que marcan tendencias permiten nutrirnos de conocimiento y reinterpretarlo para aplicarlo a ED. Pautas publicitarias en facebook y google adwords con segmentación acorde (pymes latinoamericanas) sumado a una campaña de email marketing desarrollada a medida para darse a conocer y brindar información de valor en cada envío. La base de datos de la misma se compondrá de las empresas inscriptas en las cámaras de comercio y las cámaras de exportadores de los países de la región.

Por otro lado, la presencia activa en iniciativas para la Internacionalización como lo es el Portal Connect to Americas u organismos mixtos como Fundación Exportar; generando encuentros de intercambio y alianzas estratégicas que permitan potenciar la visibilidad de ED en el mercado local y en mercados potenciales.

Asistencia anual a eventos comerciales donde se promueven y presentan nuevos productos, se posicionan marcas, se conoce el mercado regional y mundial. Enfocados en la segmentación de mercado tales como: "ExpoCruz" Feria Internacional de Santa Cruz, Multisectorial en Bolivia,

Y por otro lado, también dirigidos al mercado en general, gestionadas y avaladas por Fundación Exportar: "Maison et objet", sector: conocimiento, servicios y diseño llevada a cabo en Francia; "Tokio Room”, sector: conocimiento, servicios y diseño llevada a cabo en 
EXPORTACIÓN DE SERVICIOS DE DISEÑO E IDENTIDAD CORPORATIVA DESDE EL ESTUDIO DEMARO

Japón. Destinada a un servicio en particular: Mip Junior, sector: audiovisual y multimedia en Francia; MIPCOM Feria de Contenidos Audiovisuales, sector: audiovisual y multimedia en Francia.

Armado de material académico para blogs especializados y conferencias en eventos del sector y/o aledaños demostrando la pericia y los casos de éxito de ED posicionando la metodología y el proceso de trabajo.

Visitas anuales a los países seleccionados para conocer la cultura de negocios y generar contactos.

\subsection{Plan de acción. Implementación.}

Se trabajará en base al modelo Lean Start Up el cual define un producto mínimo viable y está abierto de forma continua a modificar, cambiar y reformular aspectos que así se requieran para enfocarse en cómo construir valor en la unidad estratégica de internacionalización de ED. Asimismo, el circuito principal del modelo: crear, medir, aprender, nos permitirá ajustar y reformular los aspectos necesarios para que el aprendizaje validado y el feedback sean dos pilares claves en la ejecución e implementación del plan promoviendo la innovación continua.

La unidad de negocio se compondrá de dos personas a cargo del área de Marketing Internacional, una orientada a la administración de negocios internacionales, otra con un rol asociado a la disciplina del diseño y a su vez con capacidades de marketing internacional. Asimismo se formarán contactos para que actúen de manera freelance como nexos en cada país, asistiendo a los clientes con encuentros presenciales si así se requiere. Contando además con el asesoramiento especializado en la legislación y la reglamentación tributaria de los países en cuestión mediante profesionales especialistas en derecho internacional.

El espacio físico tendrá lugar en la ciudad de La Plata en la ubicación actual de ED: 33 Nro 688 PA; se puede contemplar a futuro abrir un espacio independiente que mantenga áreas comunes con el equipo local. 
EXPORTACIÓN DE SERVICIOS DE DISEÑO E IDENTIDAD CORPORATIVA DESDE EL ESTUDIO DEMARO

\subsubsection{Descripción de metodología de trabajo de Estudio Demaro}

Al inicio se lleva a cabo una reunión de clarificación estratégica vía skype que permite detectar la necesidad del comitente, estableciendo un diálogo que permite conocer al grupo humano detrás del equipo de trabajo de la empresa para lograr empatía y mayor nivel de conexión profesional.

En segunda instancia se arma una propuesta de trabajo que detalla el proceso, desde los objetivos de los servicios a brindar hasta los tiempos y etapas de los mismos. Acompañado de una propuesta económica. Su envío se acompaña de una llamada telefónica para despejar dudas o realizar observaciones.

Una vez aprobada la propuesta económica se procederá a la firma de un contrato internacional de prestación de servicios (ver Anexo VIII) dando un marco corporativo creíble y sólido.

Comenzado el desarrollo del servicio se plantean comunicaciones periódicas con el comitente informando acerca de los hitos y momentos relevantes como así también pequeños informes quincenales acerca del proyecto para no perder el contacto y generar un vínculo fuerte.

La presentación del proyecto se lleva a cabo de dos formas: online o presencial. Se produce una devolución inicial en donde se destacan las fortalezas y/o aciertos del servicio; se pauta un período de análisis y visualización del material entregado (archivo . pdf y .mov) para luego recibir un feedback detallado acerca del proyecto para realizar los ajustes necesarios y proceder a la entrega de originales finales ya sea para la implementación o producción de impresos.

\subsubsection{Implementación del Plan de Marketing}

\section{Primera etapa}

En los inicios se hará foco en la promoción: dar a conocer ED y posicionarlo en el mercado objetivo, haciendo especial hincapié en la ejecución de la estrategia de comunicación:

-Campaña de Email Marketing: dos envíos por mes durante seis meses; temáticas específicas de ED y aportes teóricos y de tendencias de diseño en pymes latinoamericanas; 
EXPORTACIÓN DE SERVICIOS DE DISEÑO E IDENTIDAD CORPORATIVA DESDE EL ESTUDIO DEMARO

-Envío de brochure con servicios y casos de éxitos a empresas especialmente seleccionadas por su perfil y contacto con distribuidores;

-Artículos en medios especializados: sobre el impacto del diseño de la performance de la empresa; sobre la consultoría de diseño, comunicación, marketing y sentido común, acerca del diseño en Latinoamérica;

-Asistencia a ferias comerciales y eventos del sector con una propuesta presencial innovadora que genere curiosidad tanto en el público objetivo como en el general.

- Viajes a mercados de destino, encuentros y reuniones con colegas y proveedores.

\section{Segunda etapa}

En concordancia con lo experimentado en la primera etapa se harán los ajustes pertinentes y se proseguirá a profundizar los vínculos con los clientes adquiridos mediante estrategias de fidelización. Al mismo tiempo se continuarán delineando acciones puntuales de comunicación, patrocinio de eventos o ferias del sector y presencias académicas para lograr sinergia con la etapa anterior y profundizar el posicionamiento como un estudio de diseño y comunicación personalizado, argentino y de calidad.

- Encuentros presenciales o virtuales con grupos de clientes exteriores afines para hablar acerca de la experiencia y la perfomance de aplicar diseño estratégico en sus empresas;

- Visitas a los países donde se hayan realizado exportaciones para nutrirnos de la cultura, conocer más en profundidad los sectores productivos y de servicios para desarrollar nuevas propuestas;

- Seguimiento personalizado de los proyectos realizados y encuesta de satisfacción a los clientes, tener una mirada post proyecto que permita ponderar aspectos de la metodología de trabajo y reveer aquellos que deben reformularse.

- Revisión financiera de la inversión y las ganancias, ajustes en presupuestos y definición de la nueva inversión. 


\subsection{Conclusiones del Plan de Marketing Internacional}

Cada parte integrante del mix de marketing es importante para generar un plan sinérgico y solvente que apunte a la internacionalización de ED con bases estables y que permita superarse con el tiempo. El plan antes expuesto le permite a ED tener en claro los principales pilares para lograr el objetivo:

- brindar sus servicios de manera diferencial: el valor agregado de la consultoría;

- dirigirse a un segmento con gran potencial: pymes latinoamericanas que exportan;

- posicionarse con un precio por encima de la media que connote la calidad del servicio;

- penetrar en los mercados mediante diferentes canales de acceso: tanto de manera directa como indirecta;

- con un fuerte desarrollo en promoción y comunicación con acciones puntuales de:

presencia de marca, posicionamiento de perfil experto, contacto contínuo con el sector para promover alianzas y abordaje de clientes con foco en la flexibilidad y el feedback.

El estilo de implementación del Plan de Marketing desarrollado debe verse teñido de conceptos y formas de abordaje basadas en el modelo Lean Start Up. Esto quiere decir, que cada acción debe estar permeable al feedback y debe poder rápidamente reformularse para ejecutarse de manera óptima y potenciar los resultados. Es indispensable estar abiertos y alertas a que surgan nuevas oportunidades y a detectar los vacíos proyectuales. 
EXPORTACIÓN DE SERVICIOS DE DISEÑO E IDENTIDAD CORPORATIVA DESDE EL ESTUDIO DEMARO

\section{CONCLUSIONES}

El mercado internacional de servicios está en franca expansión y con perspectivas de un crecimiento que va a requerir de rápida respuesta y versátilidad por parte de las empresas de servicios. La exportación de servicios en Latinoamérica es un negocio incipiente con gran potencial por sus atributos y características: cultura, mística, talento y flexibilidad. El diseño y la identidad corporativa está siendo considerados como un valor agregado necesario para mejorar el desempeño de las empresas.

Desarrollaremos la presencia exportadora de ED apalancándonos en las disciplinas exportables ya maduras o en auge: la publicidad y la industria audiovisual. Potenciaremos la posición privilegiada de ED en este contexto por la calidad de la cultura corporativa, la adaptabilidad a condiciones adversas y variables; la capacidad de decodificar la necesidad del cliente y brindarle un entregable (marca, comunicación, web o material audiovisual) que va más allá de lo imaginado o esperado.

Haremos foco en la pericia de ED en diseño comunicacional que permite lograr ventajas competitivas para ejecutar la estrategia de concentración de mercados, penetrando en pequeñas y medianas empresas con características similares y de diferentes países latinoamericanos, detectando el punto o vacío para agregarle valor a cada proyecto.

Apuntaremos al ingreso de ED al mercado internacional desarrollando una serie de iniciativas a largo plazo basadas en la calidad de los servicios brindados, que produzcan vínculos sólidos con empresas latinoamericanas de distintos sectores y con empresas complementarias, colegas y potenciales agentes "distribuidores".

Para ello hemos delineado este plan de marketing que se caracteriza por su habilidad para adaptarse y replantear aspectos que sean necesarios, siendo actualizado con frecuencia de acuerdo a los sucesos y las necesidades, respondiendo siempre a una estrategia en tiempo real. Es decir, que con el monitoreo del plan haremos foco en hacer ajustes, cambios 
y toda acción que conlleve la buena ejecución de la estrategia planteada.

La unidad de negocio tendrá independencia operativa de ED junto a una personalidad propia como parte de la estrategia creativa para posicionarse en el mercado: servicios de diseño de calidad superadores. Potenciaremos el estilo de ED basado en la empatía y el involucramiento con el management de las empresas y el espíritu emprendendor. Enfatizaremos el valor agregado del perfil de ED: interpretar y descubrir las necesidades de los clientes reaccionando frente a ellas con propuestas visionarias que apunten a resultados que trasciendan.

ED es una pyme argentina de servicios que afronta el desafío de exportar.

Posee la apertura mental para reconocer su capacidad de generar negocios internacionales, apalancada por un fuerte equipo humano y priorizando la herramienta estratégica y táctica que le permitirá cumplir su objetivo de manera sostenida en el tiempo: el plan de marketing internacional desarrollado en esta tesina. 
EXPORTACIÓN DE SERVICIOS DE DISEÑO E IDENTIDAD CORPORATIVA DESDE EL ESTUDIO DEMARO

\section{ANEXOS}

\section{Anexo I}

Cuadro 1.7. Participación de América Latina en el comercio mundial de servicios (en porcentaje)

\begin{tabular}{|l|l|l|l|l|l|l|l|l|l|}
\hline & 2000 & 2001 & 2002 & 2003 & 2004 & 2005 & 2006 & 2007 & 2008 \\
\hline Exportaciones & 3,1 & 3,0 & 2,7 & 2,5 & 2,4 & 2,6 & 2,6 & 2,5 & 2,6 \\
\hline Importaciones & 4,4 & 4,4 & 3,7 & 3,4 & 3,3 & 3,5 & 3,6 & 3,6 & 3,8 \\
\hline
\end{tabular}

Fuente: elaboración propia en base a datos del FMI.

Fuente: Red Mercosur. (2010). La Exportación De Servicios en América Latina: Los Casos de Argentina, Brasil y México. Uruguay. Recuperado 17 de junio de 2014 de http://www.redmercosur.org/la-exportacion-de-servicios-en-america-latina-los-casos-deargentina-brasil-y-mexico/publicacion/170/es/tem_12/

\section{Anexo II}

Cuadro 1.9. Exportaciones de nuevos sectores dinámicos (NSD) de servicios en América Latina (en porcentaje)

\begin{tabular}{|c|c|c|c|c|}
\hline Pais & 2000 & 2003 & 2006 & 2008 \\
\hline Argentina & 6,4 & 15,4 & 17,2 & 19,1 \\
\hline Brasil & 60,0 & 50 & 53,7 & 57,1 \\
\hline
\end{tabular}

\begin{tabular}{|l|r|r|r|r|}
\hline Chile & 8,0 & 11,8 & 8,7 & 7,7 \\
\hline Colombia & 1,3 & 1,9 & 3,2 & 2,1 \\
\hline México & 10,6 & 4,8 & 3,3 & 2,0 \\
\hline Resto de América & 13,7 & 16,1 & 13,8 & 12,0 \\
\hline América Latina & 100 & 100 & 100 & 100 \\
\hline
\end{tabular}

Fuente: elaboración propia en base a datos de FMI.

Fuente: Red Mercosur. (2010). La Exportación De Servicios en América Latina: Los Casos de Argentina, Brasil y México. Uruguay. Recuperado 17 de junio de 2014 de http://www.redmercosur.org/la-exportacion-de-servicios-en-america-latina-los-casos-deargentina-brasil-y-mexico/publicacion/170/es/tem_12/ 


\section{Anexo III}

\section{Intercambio Exterior de Servicios}

(en millones de dólares)

Exportaciones

Importacioness Saldo (eje derecho)

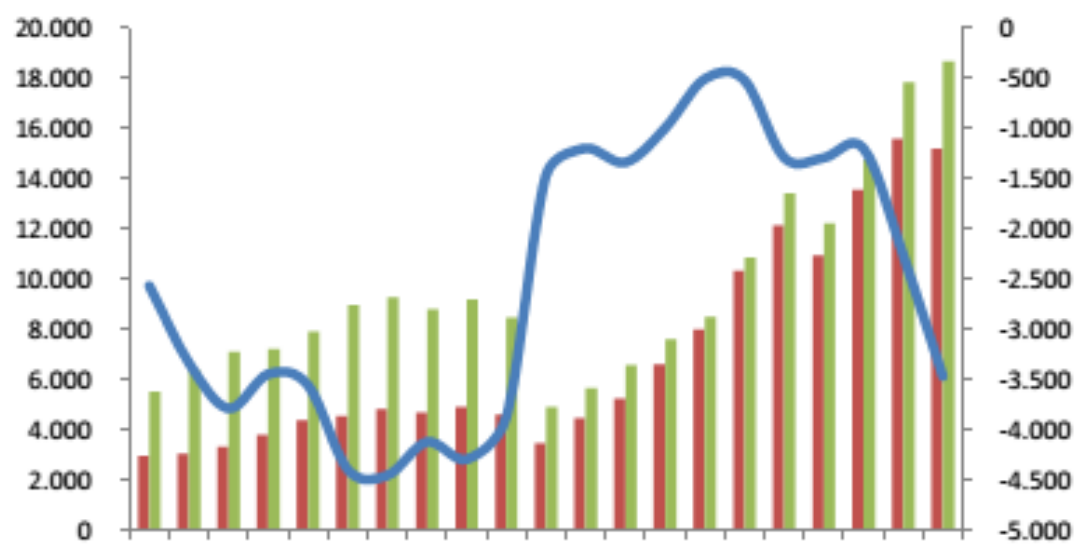

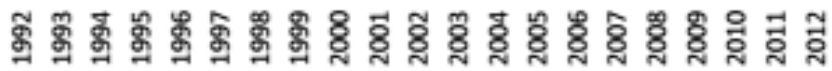

Fuente: Departamento de Economía CAC en base a INDEC

Fuente: Cámara Argentina de Comercio.(Mayo de 2013). Comercio Exterior de Servicios. Evolución y performance en 2012. Departamento de Economía. Recuperado 5 de diciembre de 2013 de http://app.kontakti.com.ar/data/mimgs/39_Informe\%20COMEX\%20Servicios\%202013 .pdf 
EXPORTACIÓN DE SERVICIOS DE DISEÑO E IDENTIDAD CORPORATIVA DESDE EL ESTUDIO DEMARO

\section{Anexo IV}

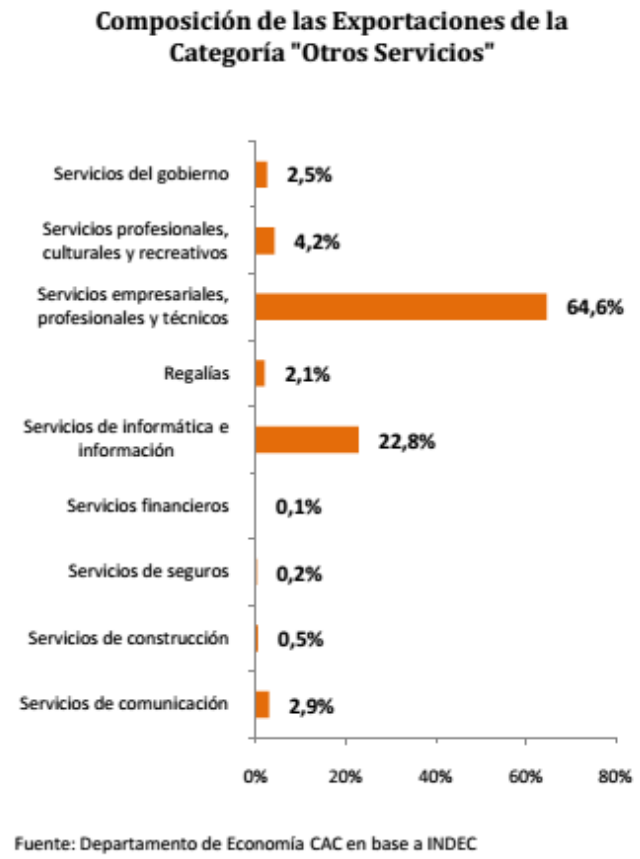

Fuente: Cámara Argentina de Comercio.(Mayo de 2013). Comercio Exterior de Servicios. Evolución y performance en 2012. Departamento de Economía. Recuperado 5 de diciembre de 2013 de http://app.kontakti.com.ar/data/mimgs/39 Informe\%20COMEX\%20Servicios\%202013 .pdf 


\section{Anexo V}

\section{Expansión reciente de las exportaciones argentinas de los servicios no tradicionales...}

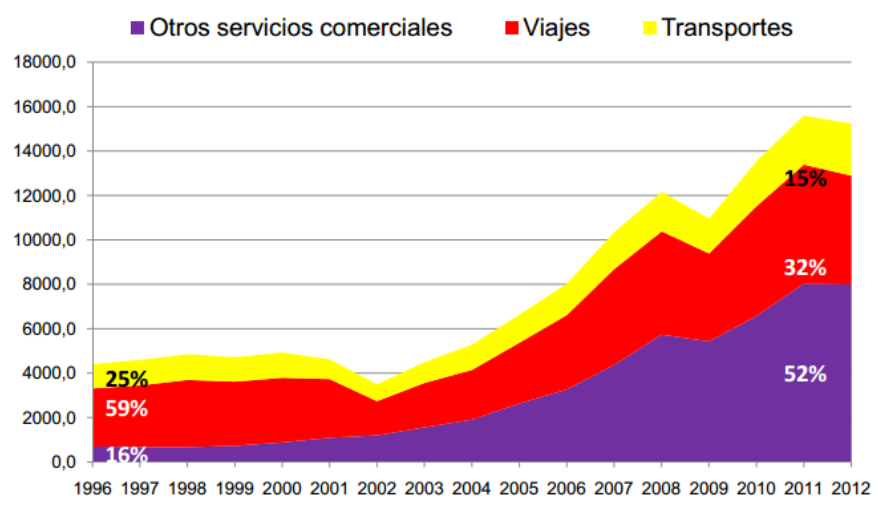

Fuente: Fundación Exportar, (Octubre 2013). La exportación de servicios comerciales argentinos. Recuperado 7 de septiembre de 2014 de

http://www.outsource2lac.com/documents/PPT_2013_sobre_Las_Exportaciones_de_Servicio s_de_Argentina-web.pdf

Tendencia decreciente del déficit del Balance de Servicios de Argentina (us\$ millones)

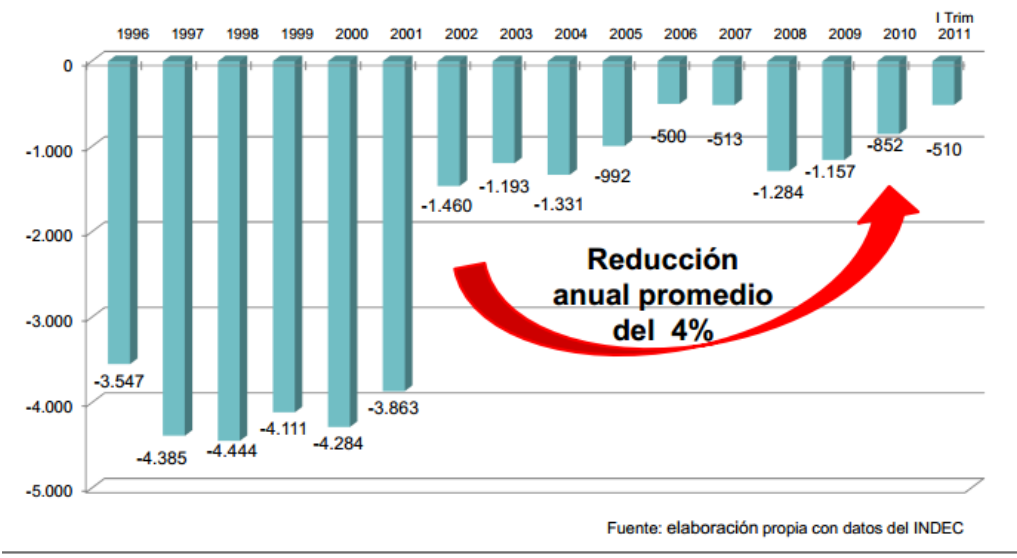

Fuente: Fundación Exportar, (Octubre 2013). La exportación de servicios comerciales argentinos. Recuperado 7 de septiembre de 2014 de

http://www.outsource2lac.com/documents/PPT_2013_sobre_Las_Exportaciones_de_Servicio s_de_Argentina-web.pdf 


\section{Anexo VI}

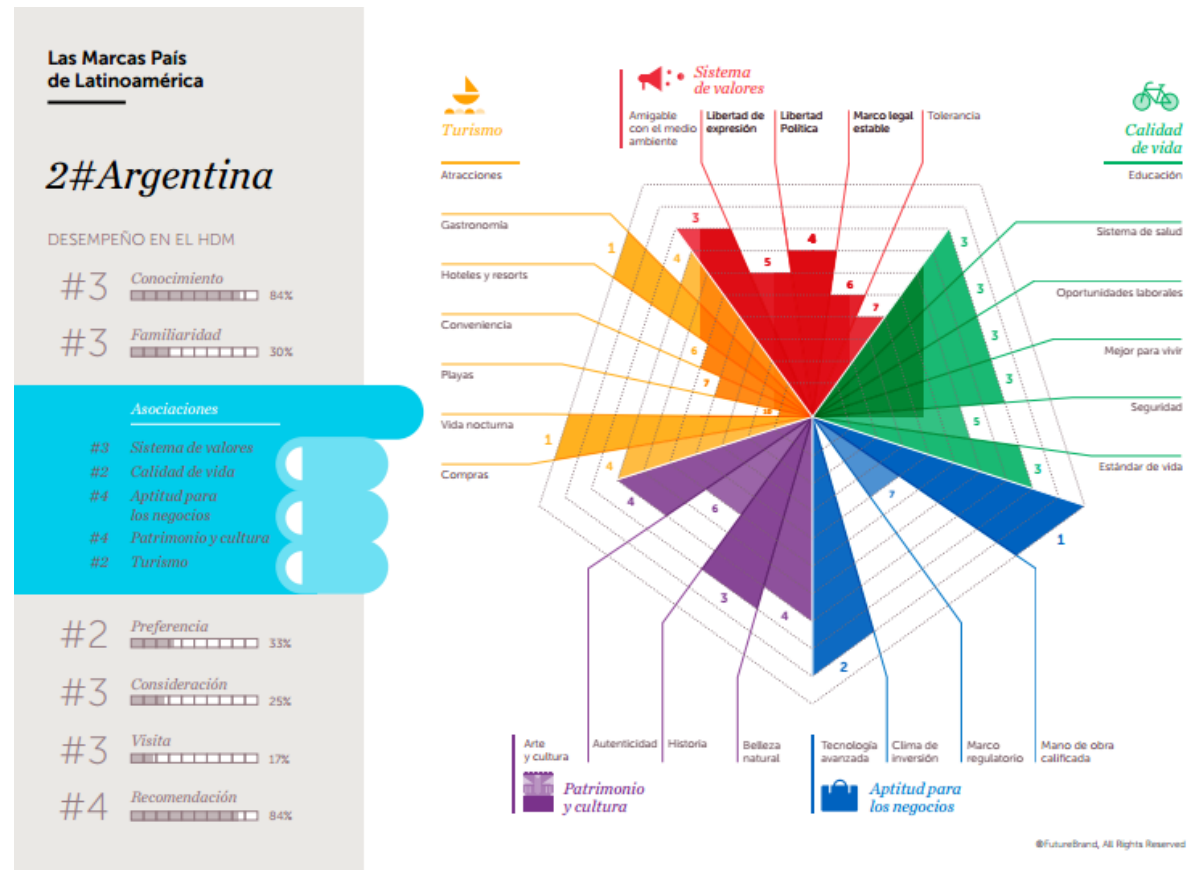

Fuente: Future Brand (2013). Country Index Latinoamérica 2013, Extraído de http://www.futurebrand.com/images/uploads/studies/cbi/CBI_Latinoamerica_2013_Es panol.pdf 
EXPORTACIÓN DE SERVICIOS DE DISEÑO E IDENTIDAD CORPORATIVA DESDE EL ESTUDIO DEMARO

\section{Anexo VII}

Presupuestos pedidos mediante la técnica de mistery shopper para conocer el rango de precios de los servicios analizados en estudios y agencias de diseño de otros países.

\section{Estudio de Diseño Casarex en Brasil http://casarex.com}

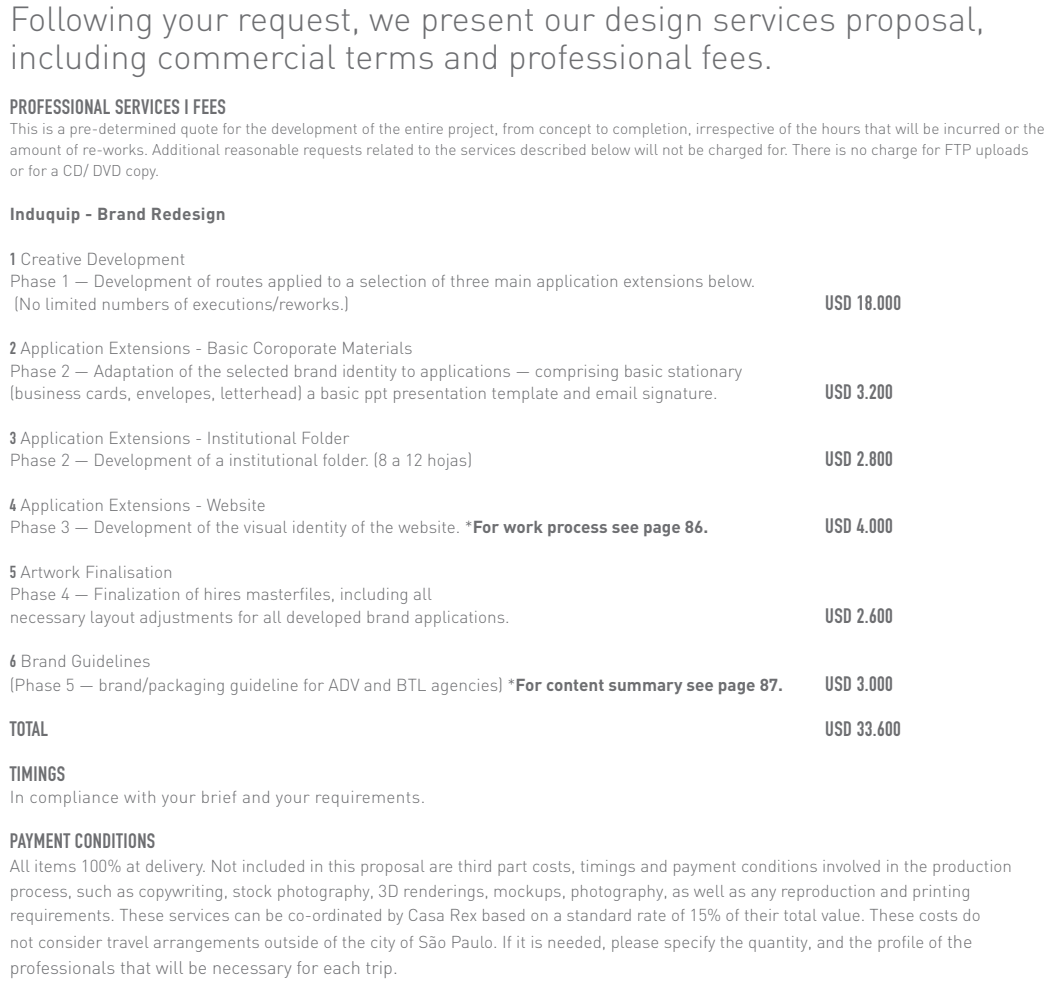




\section{Estudio de Diseño Cherry Bomb en México http://cherrybomb.com.mx}

INDUQUIP / LUCÍA MENDEZ

09-JULIO-2014
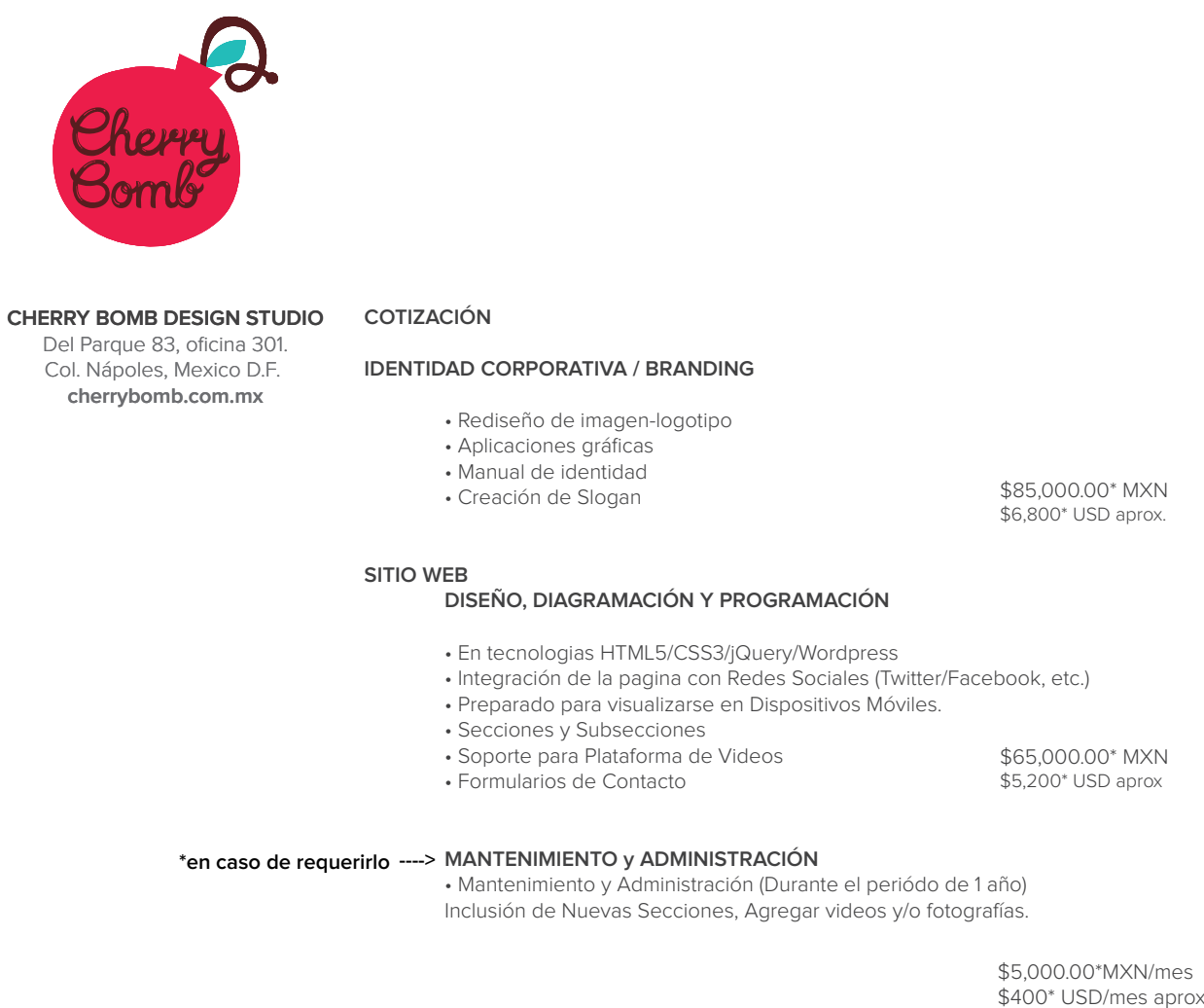


\section{Estudio de Diseño Capicua en Uruguay http://wearecapicua.com/capicuadesign.html}

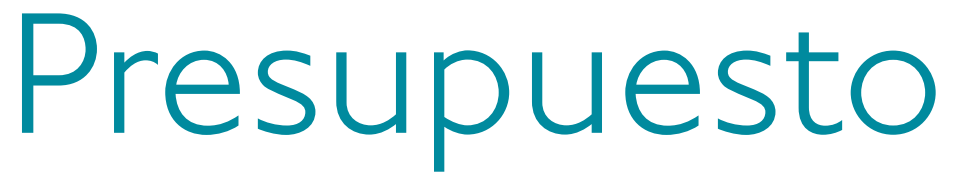

CONDICIONES GENERALES

Este es un presupuesto aproximado que dependerá de la pertinencia de la propuesta.

- El siguiente presupuesto incluye los bocetos necesarios hasta llegar a su aprobación

- Los bocetos y el proyecto se iniciarán luego de ser entregados todos los materiales e información correspondientes.

- No incluye caché, ni derechos de imagen de las personas que aparecen en las acciones los cuales son responsabilidad absoluta del cliente contratante.

- No incluye, de ser necesario, ni realización de Banda, ni derechos de autor, ni locutor el cual lo proporciona e cliente contratante.

- No incluye costos de redacción, ni de redacción creativa.

- No incluye costos de fotografías, toma de video ni edición de video.

- No incluye costos de traslados, alojamiento ni viáticos fuera de la República Oriental del Uruguay.
COSTO DE LA PROPUESTA

U\$S 3400

- El comienzo del trabajo de diseño de cualquiera de las piezas está supeditado a la comunicación por escrito o vía electrónica de la aprobación del siguiente presupuesto por parte del cliente. Y al depósito bancario del monto incial acordado.

- Estos precios no incluyen IVA, ni nigún impuesto asociado a la tarea.

- El presupuesto no incluye extras no establecidas en este presupuesto.

- El plazo de esta oferta es de 30 días. 


\section{Estudio de Diseño Magnet en España http://magnetcomunicacion.com}

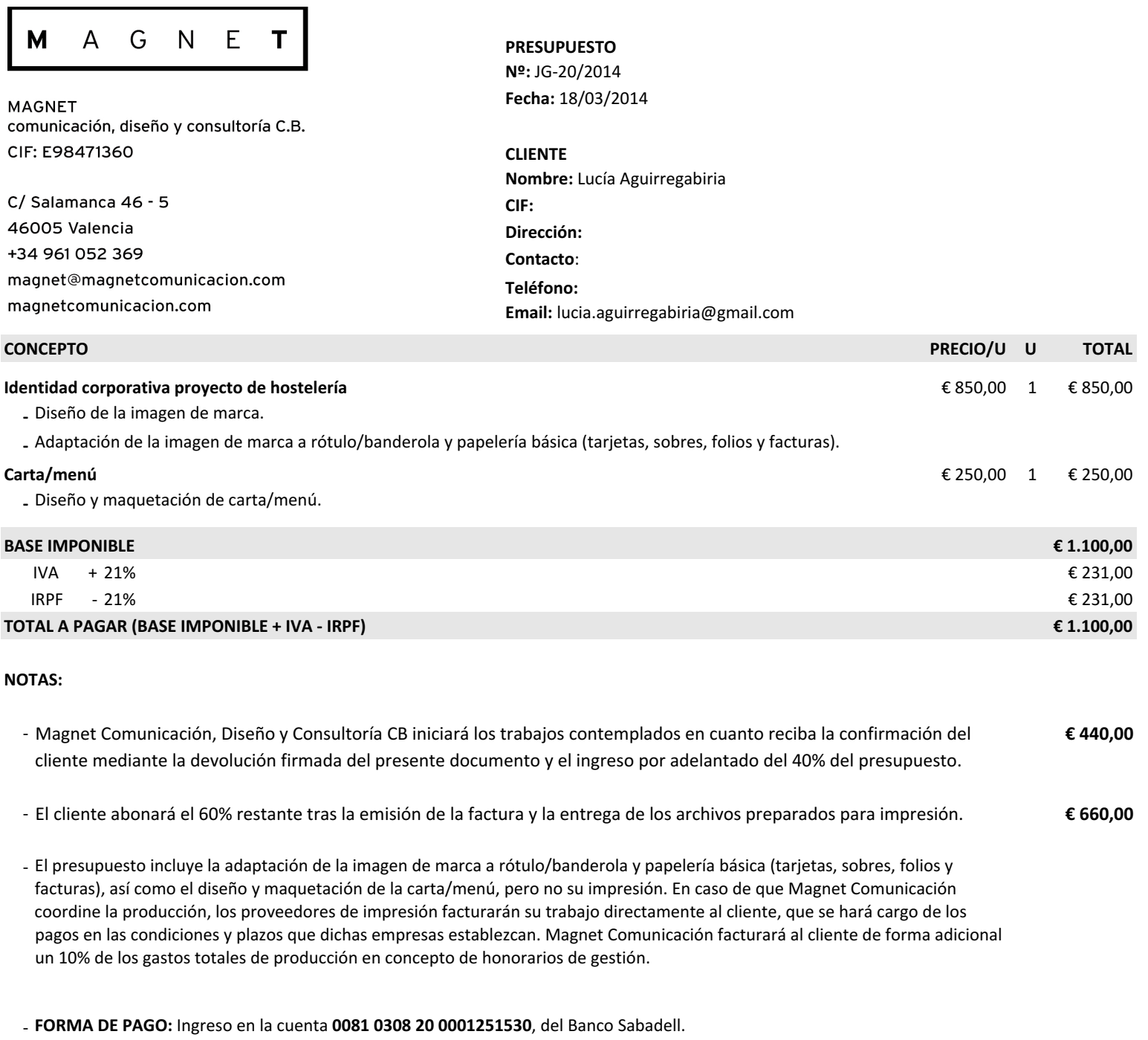

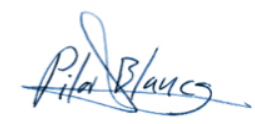


EXPORTACIÓN DE SERVICIOS DE DISEÑO E IDENTIDAD CORPORATIVA DESDE EL ESTUDIO DEMARO

\section{Anexo VIII}

Modelo de Contrato de Servicios

CONTRATO INTERNACIONAL DE SERVICIOS

Fecha: .... de ........ de 2015 en ........(Ciudad), ............(País).

DE UNA PARTE

Estudio Demaro, con domicilio en 33 nro 688, La Plata, Argentina y número de identificación / registro fiscal C.U.I.T.: 20-07698455- 8 representada por Damián Alberto Demaro, Director de Proyectos (en adelante, "el Prestador"),

Y DE OTRA,

(Razón Social de la empresa) con domicilio social en y número de identificación/ registro

fiscal......................... representada por.......................... nombre, apellido, cargo - (en adelante, "el Cliente").

MANIFIESTAN QUE:

I. El Prestador tiene como actividad principal Diseño \& Comunicación Corporativa y dispone de los conocimientos, recursos humanos y equipos necesarios para prestar este tipo de servicios.

II. El Cliente es una empresa que desea contratar servicios que ofrece el Prestador. 
III. Ambas partes, han acordado celebrar un contrato de prestación de servicios de acuerdo a los siguientes pactos:

\section{OBJETO}

El Prestador se compromete a prestar los servicios descritos en el Anexo 1 (en adelante, "los Servicios") en los términos y las condiciones que se establecen en el presente Contrato.

\section{DURACIÓN}

El Prestador realizará los Servicios objeto del presente Contrato durante el periodo de .......... - días, meses, años - desde la firma del mismo.

\section{PRECIO}

El Precio que el Cliente deberá abonar al Prestador por la realización de los Servicios objeto el presente contrato es de USD ................. Este precio no incluye los impuestos indirectos aplicables según la legislación del país del Cliente. Dicho precio se establece de acuerdo a la descripción de Servicios y Honorarios establecidos en el Anexo 1 del presente Contrato. En el supuesto de modificar o ampliar dichos Servicios, el Cliente y el Prestador se comprometen a negociar nuevos precios por los Servicios prestados.

\section{FORMA DE PAGO}

El Precio será abonado de la forma siguiente:

El Cliente pagará un $40 \%$ del precio a la firma del presente Contrato, un $30 \%$ en la fecha de A DEFINIR y un $30 \%$ en el momento que finalice la prestación de los Servicios.

\section{GASTOS Y DIETAS DE DESPLAZAMIENTO}


Todos los gastos de desplazamiento en las que incurra el Prestador (viajes, alojamiento, comidas) necesarios para el cumplimiento del Contrato serán por cuenta del Prestador.

\section{PENALIDADES}

Penalidades por incumplimiento de alguna de las partes, ej.: demora en la provisión de servicios, deficiencia en el servicio, demoras en el pago, etc. Se definirán al momento de ocurrir repercutiendo según el caso en el precio final del servicio.

\section{TRIBUNAL}

Definición de una Jurisdicción de un Tribunal, ámbito de arbitraje o mediación, que se recurrirá en el caso de alguna controversia que no pueda solucionarse por negociación. Se estipula como condición que sea un país latinoaméricano definido y consensuado por ambas partes. 


\section{BIBLIOGRAFÍA}

\section{Libros impresos}

Aaker David, Joachimstaler, E. (2005). Liderazgo de marca. Buenos Aires: Deusto.

Chaves Norberto. (1999). La imagen corporativa. Buenos Aires: Ed. G. Gilli.

Cignacco, Bruno. (2004). Fundamentos de Comercialización Internacional para Pymes. Buenos Aires: Ediciones Macchi.

Costa Joan. (2004). La imagen de marca: Un fenómeno social. Barcelona: Paidós.

Czinkota, Michael R.; Ronkainen, Ilkka A.; Moffett, Michael H. (1997). Marketing Internacional. México: McGraw Hill.

D’Ándrea Guillermo, Quelch John. (2001).Marketing Estratégico en Latinoamérica: Casos de Estudio. ( $1^{\text {a }}$ Edición). Buenos Aires: Pearson Education.

Fuentes Roberto.(2005). La Práctica del Diseño Gráfico, Barcelona: Paidós.

Kotler, Philip. (1987).Fundamentos de Mercadotecnia. México: Prentice Hall.

París, José A.(2008).Marketing Internacional, desde la óptica latinoamericana. Buenos Aires: Ed. Errepar, $1^{\mathrm{a}} \mathrm{ed}$.

Sandhusen Richard L. (2003). Mercadotecnia Internacional. México: Compañía Editorial Continental.

Taborda, Felipe y Wiedemann Julius, (2008). Latin America Graphic Design, Taschen.

Zeithaml, Valarie a. y Bitner, Mary Jo. (2002). Marketing de Servicios, Un enfoque de integración del cliente a la empresa. México: McGraw-Hill.

\section{Organismos y Entidades}

Banco Mundial (2013). Argentina. Recuperado 17 de junio de 2014 de http://datos.bancomundial.org/pais/argentina

Banco Mundial, (2015), http://www.bancomundial.org/es/country/bolivia/overview\#1

Cámara Argentina de Comercio.(Mayo de 2013). Comercio Exterior de Servicios. Evolución y performance en 2012. Departamento de Economía. Recuperado 5 de diciembre de 2013 de http://app.kontakti.com.ar/data/mimgs/39_Informe\%20COMEX\%20Servicios\%202013 
EXPORTACIÓN DE SERVICIOS DE DISEÑO E IDENTIDAD CORPORATIVA DESDE EL ESTUDIO DEMARO

. $\mathrm{pdf}$

Cámara Argentina de Comercio. (Noviembre 2010). El Rol del Sector Servicios en Argentina. Departamento de Economía. Recuperado el 10 de septiembre de http://www.cac.com.ar/documentos/59_relevancia\%20del\%20sector\%202011.pdf

Centro de Estudios para el Desarrollo Económico Metropolitano (CEDEM). (Junio 2012). La exportación de contenidos y servicios de producción televisiva en la ciudad de Buenos Aires, Un diagnóstico sobre la situación actual y las perspectivas de la industria local. Dirección General de Estadística y Censos, Ministerio de Hacienda del Gobierno de la Ciudad de Buenos Aires. Recuperado 5 de diciembre de 2013 de http://estatico.buenosaires.gov.ar/areas/hacienda/sis_estadistico/exportacion_tv_2012 junio.pdf

Centro de Estudios para el Desarrollo Exportador, (CEDEX), (s.f) Las pymes y su rol en el comercio internacional, Universidad de Palermo. Extraído el 3 de agosto de 2014 de http://www.palermo.edu/cedex/pdf/pyme_com_internacionall.pdf

Centro de Implementación de Políticas Públicas para la Equidad y el Crecimiento (CIPPEC). (Marzo 2011). Anatomía de las empresas exportadoras de servicios de la Ciudad Autónoma de Buenos Aires. Documento de Trabajo N61, Recuperado 5 de diciembre de 2013 de

http://www.cippec.org/documents/10179/51827/61+DT+IGyDP,\%20Anatom\%C3\%AD a+de+las+empresas+exportadoras+de+servicios+de+la+Ciudad+Aut $\%$ C3\%B3noma+ de+Buenos+Aires, \%20Castro,\%20Ferraro,\%202011.pdf/9314e18e-291e-4cba-b500$671285 \mathrm{e} 361 \mathrm{eb}$

CMD, Centro Metropolitano de Diseño. Offengedeen Camila, Bracuto Verona Guadalupe, Sanguinetti Marcos. (2011). Aportes del diseño, Una herramienta para mejorar el desempeño empresarial. Ministerio de Desarrollo Económico. Extraído 1 de octubre de 2013 de http://www.buenosaires.gob.ar/sites/gcaba/files/04_aportes_del_diseno.pdf

Comisión Económica para América Latina y el Caribe (CEPAL),(2013) Perspectivas económicas de América Latina 2013. Extraído 1 de octubre de 2013 de http://www.cepal.org/es/publicaciones/1463-perspectivas-economicas-de-americalatina-2013-politicas-de-pymes-para-el-cambio

Comisión Económica para América Latina y el Caribe (CEPAL). (2009). Las exportaciones de servicios de América Latina y su integración en las cadenas globales de valor. Naciones Unidas. Santiago de Chile. Recuperado 5 de diciembre de 2013 de http://www.eclac.org/publicaciones/xml/3/35963/DocW37fin.pdf

Fondo Monetario Internacional. (2004) Manual de Balanza de Pagos. 5ta edición. Recuperado el 2 de septiembre de 2014 de http://www.imf.org/external/np/sta/bop/pdf/esl/aos.pdf 
EXPORTACIÓN DE SERVICIOS DE DISEÑO E IDENTIDAD CORPORATIVA DESDE EL ESTUDIO DEMARO

Fundación Exportar, (Octubre 2013). La exportación de servicios comerciales argentinos. Recuperado 7 de septiembre de 2014 de http://www.outsource2lac.com/documents/PPT_2013_sobre_Las_Exportaciones_de_ Servicios_de_Argentina-web.pdf

Fundación Observatorio PyME. (Abril de 2013). Informe Especial: Definiciones de PyME en Argentina y el resto del mundo. Recuperado 17 de junio de 2014 de http://www.observatoriopyme.org.ar/download/informes/IE_Definicion_PyME-FOP_ Abril_2013.pdf

Instituto de Estudios Económicos sobre la Realidad Argentina y Latinoamericana (leralPyme).(Abril de 2012). La situación de las PyMEs en América Latina. Recuperado 17 de junio de 2014 de http://www.ieralpyme.org/images_db/noticias_archivos/137.pdf

Instituto Nacional de Estadísticas y Censo (INDEC). Comercio exterior 2012.

Recuperado 10 de junio de 2014 de http://www.indec.mecon.ar/ftp/cuadros/menusuperior/documentosauxiliares/com_ext_anu_2012.pdf

National Bureau of Economic Research (NBER). (2006). Measuring International Trade in Services. Working Paper12271. Recuperado 10 de junio de 2014 de http://www.fintegral.com/forhemcom/Measuring_International_Trade_in_Services_May06.pdf

Observatorio de Industrias Creativas.(15 de mayo de 2008). Informe La economía creativa en la ciudad de Buenos Aires, Delimitación y primeras estimaciones 2003-2007, Dirección de Industrias Creativas, Dirección de Comercio Exterior, Ministerio de Desarrollo Económico, Gobierno de la Ciudad de Buenos Aires. Recuperado 17 de junio de 2014 de http://oic.mdebuenosaires.gov.ar/contenido/objetos/infoecocrea.pdf

ProMexico.(2010). Mercadotecnia Internacional. Recuperado 17 de junio de 2014 de www.promexico.gob.mx

ProMexico.(2010). Plan de Negocios Internacional de Exportación. Recuperado 17 de junio de 2014 de www.promexico.gob.mx

Red Mercosur. (2010). La Exportación De Servicios en América Latina: Los Casos de Argentina, Brasil y México. Uruguay. Recuperado 17 de junio de 2014 de http://www.redmercosur.org/la-exportacion-de-servicios-en-america-latina-los-casosde-argentina-brasil-y-mexico/publicacion/170/es/tem_12/

Sistema de Información Cultural de la Argentina (SInCa). (2013). Coyuntura Cultural, Informe sobre la coyuntura económica sobre la cultura Argentina. Ministerio de Cultura. Presidencia de la Nación. Recuperado 10 de junio de 2014 de http://sinca.cultura.gov.ar/sic/publicaciones/coyunturacultural/CC05_07.pdf

UNCTAD, PNUD,(2010) “Economía Creativa: Una opción factible de Desarrollo", Informe 2010, extraído de http://unctad.org/es/Docs/ditctab20103_sp.pdf el 27 de agosto de 2013.

Unesco,(2013), extraído de http://www.unesco.org/new/es/media-services/in-focusarticles/creative-industries-boost-economies-and-development-shows-un-report/ 
EXPORTACIÓN DE SERVICIOS DE DISEÑO E IDENTIDAD CORPORATIVA DESDE EL ESTUDIO DEMARO

WTO.(2014).Acuerdo General de Servicios, Organización Mundial de Comercio. Recuperado 9 de diciembre de 2013 de http://www.wto.org/spanish/tratop_s/serv_s/gatsqa_s.htm

WTO.(1998). Advertising Services - Background Note, WTO - Council for Trade in Services. Recuperado 17 de junio de 2014 de http://ebookbrowsee.net/gdoc. php?id=144858909\&url=f98f79acfde3137fe6cacaebe7e $\underline{0928 f}$

\section{Publicaciones periódicas impresas por autor}

Levenberg, Rubén. (Junio 2011). El comercio exterior en la balanza. Pymes Plus. Nro 32.411.

Roca, Aixa. (Febrero 2014). Animación: una usina exportadora. Pymes, Cultura Emprendedora. Nro 119. 26-38.

Rolandi, Mariana. (Junio 2011). La marca, en línea con el mundo. Pymes Plus. Nro 32. 1216.

\section{Publicaciones periódicas electrónicas (Revistas o Magazines)}

Arquitectura de exportación. Caso Bórmida y Yanzón Arquitectos.(Octubre 2011). News. Newsletter de Fundación Exportar. 36-42. Recuperado 25 de abril de 2014 de http://www.exportar.org.ar/web2013/news.php

Exportación de Servicios.(Enero 2012). News. Newsletter de Fundación Exportar. 14-15. Recuperado 25 de abril de 2014 de http://www.exportar.org.ar/web2013/news.php

Índice Global de Innovación (Febrero 2014). Pymes, Cultura Emprendedora. Nro 119. 8.

Scornik, Verónica. (Enero 2012). Diseño de animación Caso Astrolab Motion. News. Newsletter de Fundación Exportar. 22-28. Recuperado 25 de abril de 2014 de http://www.exportar.org.ar/web2013/news.phpPresentaciones y conferencias

Pierini Adrián (Argentina). Exportación de Servicios de Diseño. (6 de agosto de 2012). Conglomerado de Diseño de Uruguay, [CDU MVD]. DUY 2012 - Conferencia 1er Evento anual de Diseño organizado por la Cámara y el Conglomerado de Diseño de Uruguay. Recuperado 15 de enero de 2013 de http://www.youtube.com/watch?v=_rT5tUwM9UY

Santisteban Peréz, Diego. (3 de Diciembre de 2008). Presentación General Exportación de Servicios Síntesis Plan Piloto SIC\&PYME-BID 1206 Deloitte. V Simposio sobre Comercio Exterior e Integración "Exportación de servicios. Un nuevo desafío". Consejo Profesional de Ciencias Económicas de la Ciudad Autonóma de Buenos Aires. Recuperado 9 de junio de http://www.consejo.org.ar/congresos/5comexint.htm\#mat 
EXPORTACIÓN DE SERVICIOS DE DISEÑO E IDENTIDAD CORPORATIVA DESDE EL ESTUDIO DEMARO

\section{Documentos en la web}

Chaves Norberto. (s.f). La última generación en la identidad corporativa. Recuperado 10 de diciembre de 2013 de http://www.norbertochaves.com/articulos/texto/la_ultima_generacion_en_la_identidad corporativa

Pellandra Andrea (2008). El Comercio de Servicios en los países de ALADI: Perfiles, patrón exportador y casos exitosos. Oficial de Asuntos Económicos de la División de Comercio Internacional e Integración. Recuperado 5 de septiembre de http://www.cepal.org/comercio/noticias/paginas/9/34499/04_Andrea_Pellandra.pdf

Pierini Adrián. (2011). El diseño estratégico en época de crisis. De cómo marketing y estética se fusionan para fomentar el consumo. Recuperado 6 de junio de 2014 de http://www.pierinipartners.com/material-pedagogico.php

Pierini Adrián.(2011). Diseño for export: La nueva tendencia proyectual creativa. Recuperado 6 de junio de 2014 de http://www.pierinipartners.com/material-pedagogico.php

AmCham (s.f). Cámara de Comercio de Estados Unidos en Argentina. Recuperado 5 de septiembre de http://www.amchamar.com.ar/comercio-exterior-668.html

Asociación Latinoamericana de Exportadores de Servicios.(s.f). Recuperado 6 de junio de $2014 \mathrm{http} / \mathrm{www}$.ales-lac.org

Argencon. (2013). Recuperado 6 de junio de 2014 de http/www.argencon.org

Archpartners. (s.f). Recuperado 6 de junio de 2014 de http/www.archpartners.com

Bórmida Yanzón Arquitectos, (s.f), Recuperado el 7 de abril de 2015 de http/wwwbormidayanzon.com.ar

Cámara de Comercio Exterior de Santa Fé. Recuperado 6 de junio de 2014 de http/www.comercioexterior.org.ar/

Estudio Demaro. Identidad y Comunicación. (2014). Recuperado 6 de junio de 2014 de http/www.estudiodemaro.com

Fundación Exportar. Comercio Exterior, Promoción Comercial. (2013). Recuperado 6 de junio de 2014 de http/www.exportar.org.ar/web2013/

Future Brand (2013). Country Index Latinoamérica 2013, Extraído de http://www.futurebrand.com/images/uploads/studies/cbi/CBI_Latinoamerica_2013_Es panol.pdf 
EXPORTACIÓN DE SERVICIOS DE DISEÑO E IDENTIDAD CORPORATIVA DESDE EL ESTUDIO DEMARO

Gorricho Estudio de Diseño, (s.f), Recuperado el día 9 de abril de 2015 de www.gorricho.com.ar

Octavio Getino Cine. (2012). Recuperado 6 de junio de 2014 de http/www.octaviogetinocine.blogspot.com.ar/

Pierini Partners .(2011). Diseños estratégicos que impulsan sus marcas. Recuperado 6 de junio de 2014 de http://www.pierinipartners.com/

Premios Clap. (s.f). Recuperado 6 de junio de 2014 de http/www.premiosclap.org

Sistema Integrado de Información de Comercio Exterior de Perú, Guía de Mercado de Bolivia. Extraído 14 de mayo de 2015

http://www.siicex.gob.pe/siicex/resources/fichapais/1001064218RADE9EE4.PDF

SRIAM, Sistema Regional I Armonizado (2014), Asociación Latinoamericana de Exportadores de Servicios.(s.f). Recuperado 6 de junio de 2014 http://aleslac.org/sriam/

Suplemento de Arquitectura ARQ, Diario Clarín, 9 de septiembre de 2014.

UBA, Universidad Nacional de Buenos Aires, (2015). Recuperado el 30 de abril de 2015 de http://www.uba.ar/comunicacion/detalle_nota.php?id=18693

\section{Material académico}

Presentación (2013). Administración Estratégica de la Firma, Universidad Nacional de La Plata. Profesor José Pagano.

Presentación (2012). Estrategias y políticas de Precio, Universidad Nacional de La Plata. Profesor Alberto Albarellos.

Presentación (2013). Marketing Internacional en Mercados Internacionales, Universidad Nacional de La Plata. Profesora Dra. Cristina Zapata

Presentación (2012). Políticas de Comunicación, Universidad Nacional de La Plata. Profesor Juan Katz.

Connect to Americas (2015). Curso Online Internacionalización de la empresa. https://academy.connectamericas.com/en/web//internacionalizacion-de-la-empresa-4edicion 
EXPORTACIÓN DE SERVICIOS DE DISEÑO E IDENTIDAD CORPORATIVA DESDE EL ESTUDIO DEMARO

"Declaro bajo juramento que esta tesis fue elaborada por mí, que no utilicé ningún otro material que no haya dado a conocer en las referencias y que no utilicé frases o párrafos de otros autores y que este trabajo de tesis nunca ha sido presentado ante un comité de evaluación de tesis y que no transgrede derechos de terceros."

Lucía Medina

D.N.I 31.298 .505 